\title{
Mechanism of cellular uptake and cytotoxicity of paclitaxel loaded lipid nanocapsules in breast cancer cells
}

Remya Valsalakumari ${ }^{1, \#}$, Sunil Kumar Yadava1,\#, Marzena Szwed ${ }^{2,3, \#, ~ A b h i l a s h ~ D . ~ P a n d y a ~}{ }^{4}$, Gunhild Mari Mælandsmo ${ }^{4,5}$, Maria Lyngaas Torgersen², Tore-Geir Iversen², Tore Skotland ${ }^{2}$, Kirsten Sandvig ${ }^{2,6 *} \&$ Jyotsnendu Giri ${ }^{1 *}$

${ }^{1}$ Department of Biomedical Engineering, Indian Institute of Technology, Hyderabad, India

${ }^{2}$ Department of Molecular Cell Biology, Institute for Cancer Research, Oslo University Hospital, The Norwegian Radium Hospital, Oslo, Norway

${ }^{3}$ Department of Medical Biophysics, Institute of Biophysics, University of Lodz, Lodz, Poland.

${ }^{4}$ Department of Tumor Biology, Institute for Cancer Research, Oslo University Hospital, The Norwegian Radium Hospital, Oslo, Norway

${ }^{5}$ Institute of Medical Biology, The Arctic University of Norway, University of Troms $\varnothing$, Troms $\emptyset$, Norway

${ }^{6}$ Department of Biosciences, University of Oslo, Oslo, Norway

${ }^{\#}$ Contributed equally

*Correspondence:

Dr. Jyotsnendu Giri

Email: jgiri@bme.iith.ac.in

Contact: +91- 9701277518/ +91-423017115

\section{Dr. Kirsten Sandvig}

Email: ksandvig@ radium.uio.no

Contact: +4722781828 


\section{Biodistribution}

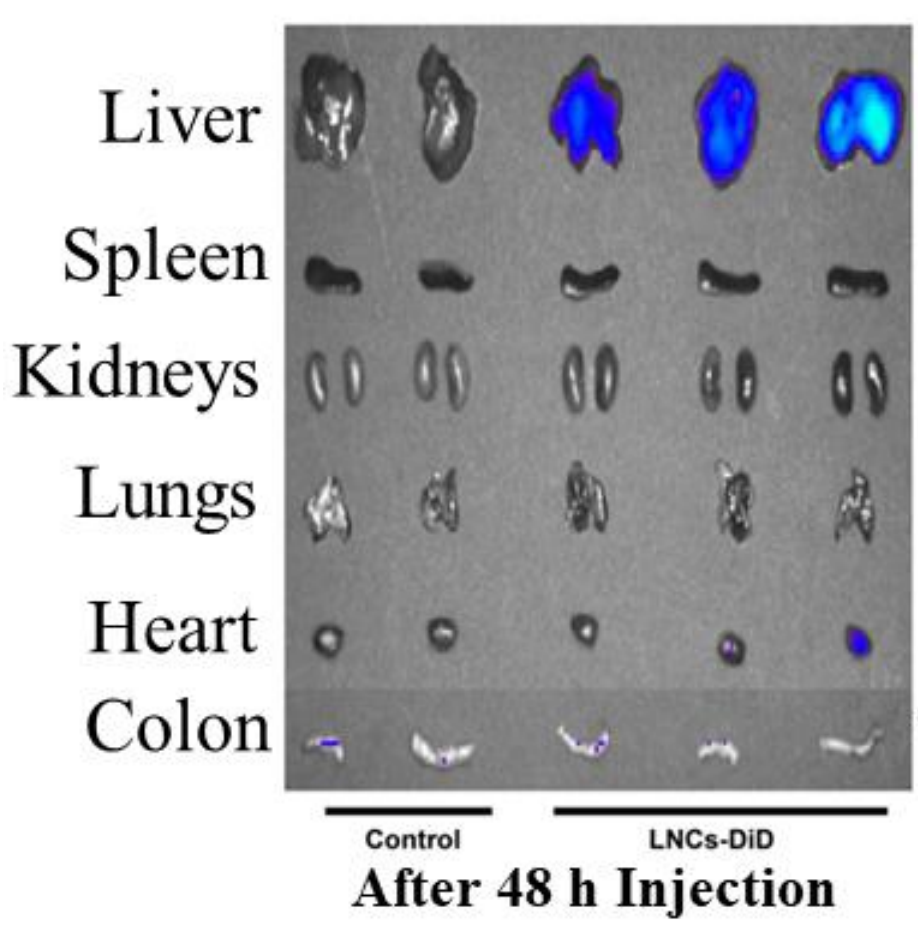

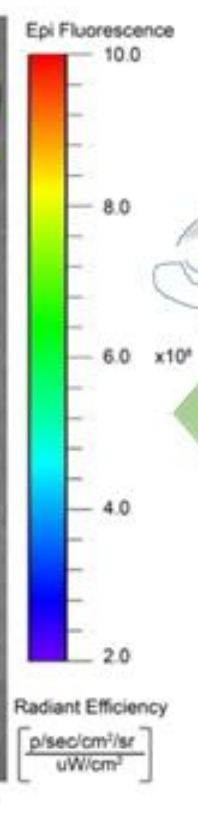

Anticancer efficacy (Breast Cancer Cells)

LNC/LNC-PTX $(50,90,120 \mathrm{~nm})$

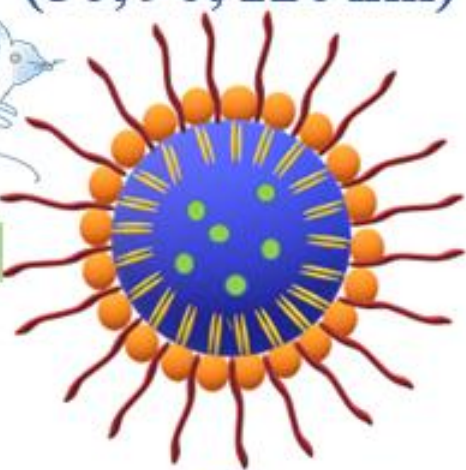

\section{Mechanism of Internalization}

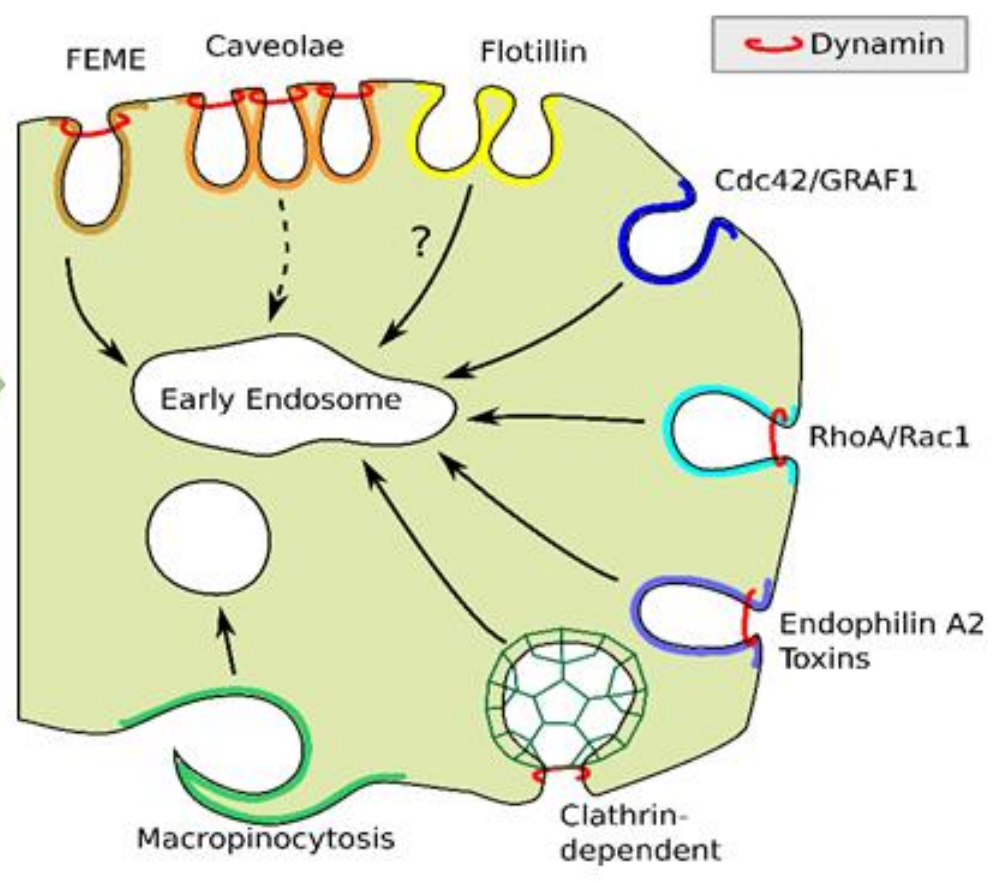

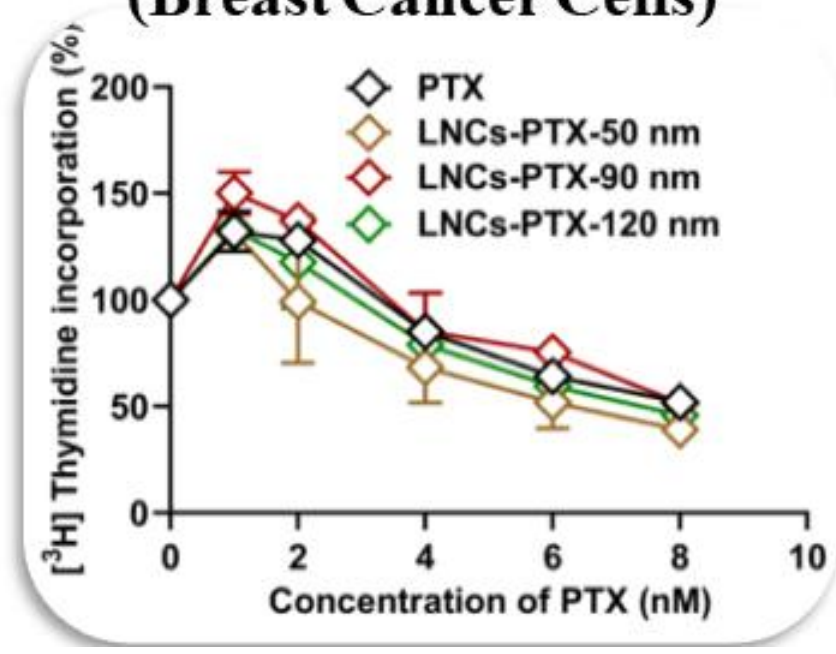

Macropinocytosis 


\section{Abstract}

Lipid nanocapsules (LNCs) have proven their efficacy in delivering different drugs to various cancers, but no studies have yet described their uptake mechanisms, paclitaxel (PTX) delivery or resulting cytotoxicity towards breast cancer cells. Herein, we report results concerning cellular uptake of LNCs and cytotoxicity studies of PTX-loaded LNCs (LNCs-PTX) on the three breast cancer cell lines MCF-7, MDA-MB-231 and MDA-MB-468. LNCs-PTX of sizes $50 \pm 2 \mathrm{~nm}, 90 \pm$ $3 \mathrm{~nm}$ and $120 \pm 4 \mathrm{~nm}$ were developed by the phase inversion method. Fluorescence microscopy and flow cytometry were used to observe the uptake of fluorescently labeled LNCs and cellular uptake of LNCs-PTX was measured using HPLC analyses of cell samples. These studies revealed a higher uptake of LNCs-PTX in MDA-MB-468 cells than in the other two cell lines. Moreover, free PTX and LNCs-PTX exhibited a similar pattern of toxicity towards each cell line, but MDAMB-468 cells appeared to be more sensitive than the other two cell lines, as evaluated by the MTT cytotoxicity assay and a cell proliferation assay based upon $\left[{ }^{3} \mathrm{H}\right]$ thymidine incorporation. Studies with inhibitors of endocytosis indicate that the cellular uptake is mainly via the Cdc42/GRAFdependent endocytosis as well as by macropinocytosis, whereas dynamin-dependent processes are not required. Furthermore, our results indicate that endocytosis of LNCs-PTX is important for the toxic effect on cells. Western blot analysis revealed that LNCs-PTX induce cytotoxicity by means of apoptosis in all the three cell lines. Altogether, the results demonstrate that LNCs-PTX exploit different mechanisms of endocytosis in a cell-type dependent manner, and subsequently induce apoptotic cell death in the breast cancer cells here studied. The article also describes biodistribution studies following intravenous injection of fluorescently labeled LNCs in mice.

Key words: Lipid nanocapsules, Paclitaxel, Breast cancer cells, Cellular uptake, Apoptosis, Biodistribution 


\section{Introduction}

According to WHO breast cancer is the most frequent cancer in women globally and accounts for $15 \%$ of total cancer deaths among women in 2018. Even though early diagnosis and combinational treatment modalities have significantly improved the patient outcome over the past years, there are major challenges such as severe and long-lasting side effects, therapeutic resistance and relapse in patients (Cao et al., 2018). Taxanes, as well as anthracyclines, are key chemotherapeutic agents for early as well as advanced breast cancer alone or in combination, or along with other approaches such as surgery, radiotherapy and immunotherapy (Apfelthaler et al., 2018; Logan et al., 2019; Petrelli et al., 2010; Vittorio et al., 2018). Paclitaxel (PTX) is a taxane, widely used in the treatment of breast cancer, ovarian cancer and a number of other cancers (Ma \& Mumper, 2013). Because of the poor aqueous solubility of PTX, associated toxicity of solubilizers (such as Cremophor $\mathrm{L}$ in the Taxol formulation) and limited bioavailability of PTX, alternative nanomedicines have been developed to exclude the toxic solubilizers and improve bioavailability and efficacy (Guan et al., 2020). Abraxane ${ }^{\circledR}$ (PTX bound in albumin-based nanoparticles) was approved by the Food and Drug Administration (FDA) in January 2005 and by the European Medicines Agency (EMEA) in 2008 for the treatment of metastatic breast cancer since it showed better efficacy than PTX (Petrelli et al., 2010). Other PTX-containing nanoformulations such as Genexol PM®, NK-105, Paclical®, Lipusu ${ }^{\circledR}$, PICN, SB05, LEP-ETU and Triolimus have also been tested in the clinic without giving a better efficacy than Abraxane ${ }^{\circledR}$ (Chowdhury et al., 2019).

During the recent years, many nanocarrier vehicles have been studied for encapsulation and delivery of PTX to tumors (Ma \& Mumper, 2013). The advantages of using such biodegradable and non-toxic nanocarriers are that they can protect the drug from degradation, 
increase the half-life of the drug in circulation, provide an improved pharmacokinetic profile and reduce systemic toxicity (Mattu et al., 2013; Shi et al., 2017; Torchilin, 2014). Moreover, passive targeting and accumulation to the tumor site due to the Enhanced Permeability and Retention (EPR) effect may also be beneficial (Peng et al., 2020). The EPR effect is based on the hyperpermeability of leaky tumor vasculature which facilitates entry of particles into the tumor interstitial space. Due to the absence of an efficient lymphatic drainage, the particles are accumulated and trapped within this tumor vicinity (Matsumura \& Maeda, 1986; Prabhakar et al., 2013). So far, there are no clear data showing the preferential size of NPs to be used for cancer therapy, but most researchers focus on the use of NPs with a hydrodynamic diameter of less than $200 \mathrm{~nm}$. Since it is known that intravenous injection of NPs with a diameter of $5 \mathrm{~nm}$ will result in approximately half the injected dose being rapidly excreted in urine and that there will be almost no renal excretion of NPs of $10 \mathrm{~nm}$ (Choi et al., 2007), NPs used for cancer therapy should be larger than $10 \mathrm{~nm}$. Many studies are based on NPs with a hydrodynamic diameter of $90 \mathrm{~nm}$, which is similar to the first drug-encapsulated NP entering the market, i.e. Doxil $^{\circledR} /$ Caelyx ${ }^{\circledR}$ (doxorubicin encapsulated in liposomes). In the present study we have chosen to make LNCs of three sizes, 50, 90 and $120 \mathrm{~nm}$. We included smaller LNCs $(50 \mathrm{~nm})$ because they potentially could penetrate better into tissue and they are sufficiently small to be internalized by all known endocytic mechanisms (Sandvig et al., 2018). The largest LNCs (120 nm) were included because more drug can be encapsulated in these LNCs. However, the $120 \mathrm{~nm}$ LNCs are too large to be taken up by caveolae, most often stated to form vesicles with a diameter of $50-80$ nm (Lamaze et al., 2017).

A wide variety of nanodelivery systems based on polymers, lipids, proteins or metals have been studied so far for the delivery of PTX and other anti-cancer therapeutics (Bazak et al., 
2015; Tran et al., 2017; Xie et al., 2016; Zhai et al., 2018). LNCs are among the best studied lipid-based nanovehicles and are composed of an inner oily core made up of Labrafac ${ }^{\mathrm{TM}}$ lipophile WL 1349, a middle phase containing Lipoid S-75 and an outer hydrophilic phase obtained with the hydrophilic surfactant, Kolliphor HS 15. These particles, in an aqueous phase suspension, remain stable for more than six months at $4{ }^{\circ} \mathrm{C}$ (Heurtault et al., 2002). Moreover, all components in these LNCs are approved by FDA for oral, topical and parenteral administration (Huynh et al., 2009). Efficacy of PTX loaded formulations have been demonstrated in C6 glioma tumor cell line and experimental tumor models of glioblastoma, hepatocellular carcinoma and lung carcinoma (Hureaux et al., 2010; Lacoeuille et al., 2007a; Lacoeuille et al., 2007b; Lollo et al., 2015). It was also reported that the Kolliphor component is an inhibitor of the P-glycoprotein (P-gp) related drug efflux system (leading to drug resistance) and should therefore be beneficial, since PTX is a substrate for the P-gp protein (Roger et al., 2010). This contributes to the more promising nature of LNCs for PTX delivery.

PTX is commonly used in treatment of breast cancer, but the possibility to use LNCs-PTX for treatment of breast cancer and the mechanism of cellular uptake in breast cancer cells have so far not been studied. We hereby report studies on the uptake mechanisms and toxicity induced by PTX loaded LNCs in breast cancer cell lines. In the present study, the efficacy of different sized (50, 90 and $120 \mathrm{~nm}$ ) PTX loaded LNCs against three breast cancer cell lines were studied. These cell lines differ in their characteristics and molecular profile in the following way: MCF-7 (luminal A, ER+, PR+, Her 2-), MDA-MB-231 (claudin low, ER-, PR-, Her 2-) and MDA-MB468 (basal, ER-, PR-, Her 2-) (Holliday \& Speirs, 2011). The data presented show that LNCs are promising drug carriers and further efficacy studies on experimental and preclinical models of breast cancer should be performed. 


\section{Materials and Methods}

\subsection{Materials}

Kolliphor® HS 15 (Polyethylene glycol (15)-hydroxystearate), PTX, DMEM and RPMI 1640 medium, dimethyl sulfoxide (DMSO), tetracycline, bovine serum albumin (BSA), Triton X-100, NP-40, sodium deoxycholate, SDS, n-octyl $\beta$-D-glucopyranoside 3-(4,5-dimethyl- 2-thiazolyl)2,5-diphenyl-2H-tetrazolium bromide (MTT; cat\#M5655), and penicillin/streptomycin (Pen/Strep P4333) were obtained from Merck (Germany). Labrafac ${ }^{\mathrm{TM}}$ lipophile WL 1349 (medium-chain triglycerides of caprylic (C8) and capric (C10) acids) were gifts from Gattefosse, Germany. Lipoid S-75 (fat free soybean phospholipids with 70\% phosphatidylcholine) was obtained from Lipoid, Germany. For western blotting, the following antibodies were used: PARP (\#9542), cleaved caspase-3 (\#9661) from Cell Signaling Technology, Danvers, MA and $\gamma$-tubulin (Sigma Aldrich). Milli-Q water was freshly prepared from the Millipore Milli-Q Biocell water purification system. All other chemicals and solvents were of high analytical quality.

\subsection{Cell lines}

The breast cancer cell lines, MCF-7, MDA-MB-231, and MDA-MB-468 were obtained from the American Type Culture Collection (Manassas, VA). Cells were grown as monolayer cultures using suitable media; RPMI (MCF-7, MDA-MB-231) or DMEM (MDA-MB-468) supplemented with $10 \%$ FBS, penicillin $(10 \mathrm{U} / \mathrm{mL})$ and streptomycin $(50 \mu \mathrm{g} / \mathrm{mL})$ under standard conditions: 37 ${ }^{\circ} \mathrm{C}, 100 \%$ humidity, with an atmosphere of $5 \% \mathrm{CO}_{2}$ and $95 \%$ normal air. The HeLa K44A cell line, stably transfected with the cDNA for dynK44A, was a gift from Professor S.L. Schmid, Department of Cell Biology, Dallas, USA. As described previously, the cells were cultured in the absence or presence of tetracycline (Damke et al., 1995). All cultured cells were monitored for Mycoplasma contamination. 


\subsection{Development of PTX and DiD loaded LNCs}

LNCs were prepared by phase-inversion method as described previously (Heurtault et al., 2002). Briefly, the constituent of the LNCs, Labrafac ${ }^{\mathrm{TM}}$ lipophile WL 1349 (47.6 or 64.4 or $65.5 \%$, w/w), Lipoid S-75 (4.7 or 4.9 or 3.0\%, w/w) and Kolliphor® HS 15 (47.6 or 30.7 or 30.0\%, w/w) were mixed together followed by addition of $1.80 \mathrm{~mL}$ of aqueous $\mathrm{NaCl}$ solution $(10 \% \mathrm{w} / \mathrm{v})$ per 1 $\mathrm{g}$ of ingredients as dispersant phase to obtain LNCs of 50, 90 and $120 \mathrm{~nm}$, respectively. Subsequently, the mixtures were heated under magnetic stirring up to $90{ }^{\circ} \mathrm{C}$ to ensure that phase inversion temperature has passed. The mixture was then cooled down to $60{ }^{\circ} \mathrm{C}$. This process was repeated for three cycles $\left(60{ }^{\circ} \mathrm{C} \leftrightarrow 90{ }^{\circ} \mathrm{C}\right)$ and at the end of $3^{\text {rd }}$ cycle, keeping the temperature above phase inversion temperature; cold water was added to obtain the LNCs having average size of 50, 90 and $120 \mathrm{~nm}$. The LNCs suspension was then stirred for 5 min and stored at $4{ }^{\circ} \mathrm{C}$ for further analyses. To obtain LNCs-PTX, known quantity of PTX (w/w with respect to Labrafac) was dissolved into Labrafac prior to all preparation steps under magnetic stirring at $60{ }^{\circ} \mathrm{C}$ for 5 min. Subsequently, above mentioned steps were followed to obtain the LNCs-PTX having different sizes. DiD loaded LNCs (LNCs-DiD) of the three sizes, loaded with the same quantity of the dye ( $5 \mu \mathrm{g} / 100 \mathrm{mg}$ of LNCs), were also prepared by the same method.

\subsection{Determination of particle size and zeta potential}

In order to measure the particle size and zeta potential of LNCs-PTX or LNCs-DiD, Zetasizer Nano ZS (Malvern Instrument, London, UK) was used. Briefly, LNCs were prepared at a concentration of $1 \mathrm{mg} / \mathrm{mL}$ and filled into disposable plastic cuvette. Particle size was measured on back scattering at an angle of $173^{\circ}$ keeping 10 accumulations in triplicate. To determine zeta potential, phase analysis light scattering technique was used. A required concentration of LNCs 
was prepared and filled into disposable zeta shell. Zeta potential was measured in triplicate running the machine in automatic mode.

\subsection{Quantification of PTX and DiD}

PTX was quantified by High-Performance Liquid Chromatography (HPLC), using a chromatograph equipped with a quaternary pump, an auto sampler, a thermostat and a UV-visible detector (Waters Alliance System 2695, USA). Hypersil ${ }^{\text {TM }}$ ODS C-18 column (Thermo Fisher) was used for the separation of PTX using a mobile phase composition of acetonitrile: $0.1 \%$ aqueous acetic acid (70:30) maintaining a flow rate of $1 \mathrm{~mL} / \mathrm{min}$ and column temperature at 40 ${ }^{\circ} \mathrm{C}$. PTX was detected at $228 \mathrm{~nm}$ and unknown quantity of PTX was estimated by using a standard curve. For LNCs-DiD, suitable concentrations were prepared in acetone and quantified by measuring the absorbance at $645 \mathrm{~nm}$.

\subsection{Cryo-Scanning electron microscopy (Cryo-SEM)}

Cryo-SEM was performed to analyze the morphology of LNCs. Sample was prepared as described previously (Yadava et al., 2020). Briefly, $10 \mu \mathrm{L}$ of a suitable diluted LNCs suspension was mounted onto a carbon tape coated sample holder which was then transferred into the Cryo unit (PP3000T) by Quorum, followed by rapid cooling in liquid nitrogen $\left(-190{ }^{\circ} \mathrm{C}\right)$ for $30 \mathrm{sec}$ under vacuum. The sample was then sublimated at $-85{ }^{\circ} \mathrm{C}$ for $10 \mathrm{~min}$ and sputter-coated with gold at $10 \mathrm{~mA}$ for $45 \mathrm{sec}$ under vacuum. Subsequently, the prepared sample was moved onto a highly stable Scanning Electron Microscope (JEOL JSM-7600F) cold stage for observation and analyzed at an accelerating voltage of $5 \mathrm{kV}$.

\subsection{Determination of drug loading capacity and encapsulation efficiency}

The drug loading capacity (LC) and encapsulation efficiency (EE) of LNCs in regard with PTX were determined as previously reported (Hureaux et al., 2009) with required modifications. 
Briefly, LNCs-PTX were passed through a $0.2 \mu \mathrm{m}$ syringe filter (PES, Pall Corporation) followed by dissolution in acetonitrile. After suitable dilution in the mobile phase, samples were directly injected into HPLC system and PTX was quantified using a standard curve. The EE and LC were determined by using following equations:

$$
\begin{aligned}
& \% E E=(\text { Amount of drug quantified in LNCs/Total drug taken) } x 100 \\
& \% L C=(\text { Amount of drug quantified in LNCs/Total weight of Labrafac) } x 100
\end{aligned}
$$

\subsection{Evaluation of stability}

LNCs-PTX (1\% w/w to Labrafac) of different sizes were prepared and stored at $4{ }^{\circ} \mathrm{C}$. Samples were aliquoted at regular intervals from day 0 to day 60 , followed by passing through the $0.2 \mu \mathrm{m}$ syringe filter (Yadava et al., 2020). The samples were then dissolved in acetonitrile and the amount of PTX encapsulated within LNCs was quantified by HPLC as described above. The percentage of PTX retained within the particles with respect to the initial loading directly correlates with the stability of LNCs-PTX upon long term storage. Similarly, LNCs-DiD formulation (different size) was stored at $4{ }^{\circ} \mathrm{C}$ up to 2 months. The particles size and the fluorescence intensity of LNCs-DiD formulations were probed at periodic intervals.

\subsection{Release of PTX from LNCs}

PTX release from LNCs was determined by using a dialysis method as reported previously (Lamprecht et al., 2002). Specific amount of LNCs suspension (equivalent to $0.2 \mathrm{mg}$ of PTX) was mixed with $3 \mathrm{~mL}$ of phosphate buffer saline (PBS) containing $0.1 \%$ Tween 80 , having $\mathrm{pH}$ 7.4 or 5.0 and packed into dialysis tube. Immediately, all dialysis tubes were immersed into respective $50 \mathrm{~mL}$ falcon tubes containing $15 \mathrm{~mL}$ of PBS ( $\mathrm{pH} 7.4$ or 5.0). The tubes were then 
incubated at $37 \pm 0.5^{\circ} \mathrm{C}$ within an incubator shaker maintaining a speed of $100 \mathrm{rpm}$. An aliquot of $0.5 \mathrm{~mL}$ was withdrawn from each tube every $12 \mathrm{~h}$ and same volume was replaced with fresh PBS to maintain the sink condition. All aliquots were directly injected into the HPLC system for quantification of PTX. The amount of PTX released was quantified using a standard curve. The percent drug release from LNCs was determined by the following equation:

Drug release $(\%)=($ Drug quantified in release medium/theoretical weight of drug within nanocapsules) X 100 .

\subsection{Intracellular uptake of LNCs or LNCs-PTX}

The effect of particle size on the uptake of LNCs by breast cancer cells was assessed by flow cytometry after incubating the cells with LNCs-DiD. Briefly, MDA-MB-468 cells were seeded in a 12-well plate $\left(1.5 \times 10^{5}\right.$ cells/well) and incubated with the three preparations $(50,90$ and 120 $\mathrm{nm})$ of LNCs-DiD $(300 \mu \mathrm{g} / \mathrm{mL})$ for $3 \mathrm{~h}$ at $37{ }^{\circ} \mathrm{C}$. Cell samples were then harvested, washed and the fluorescence intensity was measured at an excitation of $623 \mathrm{~nm}$ using a red laser and detected in the RL1 channel of Thermo Attune acoustic flow cytometer aided with FACS Diva software for data acquisition. Additionally, cells were incubated with LNCs-DiD for $3 \mathrm{hr}$ and imaged by fluorescence microscopy using Olympus 1X73 microscope (Olympus, Tokyo, Japan) equipped with a 20X objective and a digital camera, Micropublisher 3.3 RTV (Teledyne Qimaging, Canada).

In order to correlate the intracellular accumulation of LNCs with the induction of cell death by PTX encapsulated within LNCs, cellular accumulation of PTX and LNCs-PTX was also determined by using HPLC. Briefly, free PTX or PTX-loaded LNCs (equivalent to $25 \mu \mathrm{M}$ PTX) was incubated with cells for 1.5 and $3 \mathrm{hr}$ at $37^{\circ} \mathrm{C}$. After incubation, the cells were washed with 
PBS to remove any loosely bound PTX. The cells were harvested by trypsinization and the cell pellets underwent ultrasonic homogenization for cell lysis. They were freeze-dried by lyophilization and PTX was extracted by chloroform. The samples were dried under vacuum and reconstituted in suitable mobile phase and analyzed by HPLC.

\subsection{Endocytosis inhibitor studies}

For endocytosis inhibition studies, cells were seeded in 24 -well plates $\left(5 \times 10^{4}\right.$ cells/well) and grown for $24 \mathrm{hr}$. Before treatment with $0.5 \mathrm{mg} / \mathrm{mL} \mathrm{LNCs}$ for $2 \mathrm{hr}$, the cells were incubated for 30 min with different inhibitors of endocytosis in RPMI medium supplemented with $1 \%$ FCS. To check whether dynamin is involved in the uptake of the LNCs we used HeLa K44A cells, which express a dominant negative mutant of dynamin in the absence of tetracycline (Damke et al., 1995). After exposure of cells to the LNCs and inhibitors for the desired time, the cells were washed with PBS, treated with Accutase VR Cell Detachment Solution (Sigma-Aldrich, St Louis, MO), pelleted, resuspended in PBS and then processed for flow cytometry. The dye was excited using a $633 \mathrm{~nm}(100 \mathrm{~mW})$ solid state red laser and detected with the 660/20 nm bandpass filter

detector LSR II UV laser (BD Biosciences, San Jose, CA) controlled by the FACS Diva software (BD Biosciences, San Jose, CA). All inhibitors were obtained from Sigma-Aldrich.

\subsection{In vitro cytotoxicity studies}

\subsubsection{MTT assay}

The cytotoxicity of free PTX and LNCs-PTX was evaluated by MTT assay as previously reported (Szwed et al., 2020). MCF-7, MDA-MB-231 and MDA-MB-468 cells were grown in suitable media under standard conditions. Cells in logarithmic phase of culture were plated at a density of $5 \times 10^{3}$ cells per well in a 96-well culture plate (Tarsons, India) for $24 \mathrm{hr}$ to attach, followed by addition of free PTX or LNCs-PTX $(0-50 \mathrm{nM})$ and incubated for predetermined 
time points such as 24,48 and $72 \mathrm{hr}$. Afterwards, the medium containing samples was aspirated out and the wells were washed with PBS. MTT solution $(0.5 \mathrm{mg} / \mathrm{mL})$ was added and incubated for $3 \mathrm{hr}$, followed by solubilization of formazan crystals by the addition of $100 \mu \mathrm{L}$ of DMSO. The plates were read with prior shaking for $15 \mathrm{sec}$ at $570 \mathrm{~nm}$ keeping $660 \mathrm{~nm}$ as reference wavelength using EnSpire multimode plate reader (PerkinElmer, USA). Cytotoxicity of the LNCPTX and free PTX was expressed as IC 50 values, which is the concentration of test material that reduces cell viability by $50 \%$ relative to the untreated control cells. In parallel with the cytotoxicity experiments, the cellular morphology changes were observed after treatment with free PTX or LNCs-PTX, $90 \mathrm{~nm}$ by phase contrast microscopy using Eclipse TS100 microscope (Nikon, Tokyo, Japan) equipped with a 20X objective and a Digital Sight camera (Nikon).

\subsection{2 $\left[{ }^{3} \mathrm{H}\right]$ Thymidine assay}

The effect of PTX loaded LNCs on cell proliferation was assessed by $\left[{ }^{3} \mathrm{H}\right]$ thymidine incorporation assay which was mentioned elsewhere (Poli et al., 2016) with slight modifications. Briefly, cells were plated at a density of $5 \times 10^{4}$ cells/well in 24-well plates and incubated for 24 hr to get attached. This was followed by replacement of media with free PTX or LNCs-PTX of different concentrations (0-8 $\mathrm{nM})$ and incubation for another $24 \mathrm{hr}$. Additionally MCF-7 cell line was incubated for $30 \mathrm{~min}$ at $37{ }^{\circ} \mathrm{C}$ with different inhibitors of endocytosis using RPMI cell growth medium supplemented with $1 \%$ FCS. The incubation was continued for next $2 \mathrm{hr}$ with various concentrations of PTX encapsulated in LNCs, $90 \mathrm{~nm}(1,2,4,6,8 \mathrm{nM})$ in the same cell growth conditions. Subsequently, the cells were washed two times with RPMI medium and grown in cell growth conditions for next $22 \mathrm{hr}$. After aspirating out the sample solutions, $\left[{ }^{3} \mathrm{H}\right]$ thymidine $(3 \mu \mathrm{g} / \mathrm{mL}$ in serum free media; $75 \mu \mathrm{Ci} / \mathrm{mL})$ was added to the cells and the incubation was continued for $30 \mathrm{~min}$ at $37^{\circ} \mathrm{C}$. This was followed by replacement of the solution 
with $5 \%$ TCA solution ( $800 \mu \mathrm{L} /$ well $)$ and incubation for $10 \mathrm{~min}$ at room temperature, which was done twice to precipitate nucleic acids and proteins and permeabilize the cells. TCA solution was aspirated out and 0.1 M KOH $(200 \mu \mathrm{L})$ was added to the wells and incubated for 15 min at room temperature, which solubilized the precipitated nucleic acids and proteins. The solution was transferred to a scintillation vial, mixed with $3 \mathrm{~mL}$ of scintillation fluid (Perkin Elmer, USA) and the radioactivity was measured for $60 \mathrm{sec}$ using a scintillation counter (Tri-Carb 2100TR, Packard Bioscience, USA).

\subsection{Immunoblotting}

To measure if LNCs-PTX induced apoptosis, MCF-7, MDA-MB-231 and MDA-MB-468 cells were incubated with the increasing concentrations of LNCs-PTX, PTX alone (3.12. 6.25, 12.5, 25, $50 \mathrm{nM})$ and LNCs $(25,50 \mathrm{nM})$ for $72 \mathrm{hr}$ at $37{ }^{\circ} \mathrm{C}$. Subsequently, the cells were subjected to lysis in $80 \mu \mathrm{L}$ of a "lysis buffer" (25 mM Tris $\mathrm{HCl} \mathrm{pH} 7.6,150 \mathrm{mM} \mathrm{NaCl}, 1 \%$ (w/v) NP-40, $1 \%$ (w/v) sodium deoxycholate, $0.1 \%(w / v)$ SDS, $0.2 \%(w / v)$ n-octyl- $\beta$-D-glucopyranoside) on ice for $10 \mathrm{~min}$. The protein concentration of the lysates was measured by the BCA assay, according to the protocol supplied by the manufacturer, mixed 1:1 with $1.5 \%(\mathrm{w} / \mathrm{v})$ SDS in lysis buffer and sonicated. Equal amounts of protein were loaded on the gel and SDS-PAGE separation was run on a 4-20\% TGX gel (Criterion, Bio-Rad, Oxford, UK). After the transfer of proteins onto a 0.2 $\mu \mathrm{m}$ PVDF membrane with Transblot Turbo (Bio-Rad) system, the membranes were blocked by drying and incubated with primary antibodies at $4{ }^{\circ} \mathrm{C}$ overnight. Finally, the membrane was probed with HRP-conjugated secondary antibodies by incubation for $35 \mathrm{~min}$ at room temperature and the proteins were detected with chemiluminescence substrate by Super Signal West Dura Extended Duration Substrate (Thermo Scientific, Waltham, MA) in a ChemiDoc Imaging System (Bio-Rad Laboratories, Hercules, CA). 


\subsection{Biodistribution study in mice}

Animal experiments were approved by the National Animal Research Authority in Norway, after first having been approved by the institutional veterinarian. All the procedures involving animals were performed according to protocols approved by the National Animal Research Authority and conducted according to the regulations of the Federation of European Laboratory Animals Science Association (Guillen, 2012). Female athymic nude foxn1nu mice were bred at the Department of Comparative Medicine, Oslo University Hospital, and kept in a pathogen-free milieu at a constant temperature $\left(21.5 \pm 0.5^{\circ} \mathrm{C}\right)$ and humidity $(55 \pm 5 \%) ; 15$ air changes/hr and a 12-hr light/dark cycle. The animals were 5-6 weeks old and their weight was 20-23 g before they were included in the experiments. Anesthesia was obtained with 5\% (v/v) Sevofluran along with 3 L nitrous oxide and 1 L oxygen, given with breathing mask. Cages were equipped with bedding, cardboard houses and paper. Food and water were supplied ad libitum. Animals were sacrificed performing cervical dislocation at the end of the experiments.

DiD labeled LNCs were used to study biodistribution in healthy mice using an in vivo imaging system IVIS ${ }^{\circledR}$ Spectrum (Perkin Elmer, MA, USA). Mice were injected intravenously with DiD labeled LNCs (90 nm, $0.8 \mathrm{mg}$ /injection); no injection in control animals. The mice were given the above-mentioned gas anesthesia using multiple masks. The excitation/emission wavelength pair of 640/680 nm was used for imaging of the LNCs. Full body images were obtained 4, 24 and $48 \mathrm{hr}$ after injection (not shown); the animals were then sacrificed, and organs were harvested. Ex vivo imaging of the organs was also performed with the IVIS ${ }^{\circledR}$ Spectrum using the same settings as above. Total signal intensity in the organs, such as liver, spleen, kidneys, lungs, heart and colon were calculated, using Living Image software (Perkin Elmer), as total radiant efficiency (Emission light $[\mathrm{photons} / \mathrm{sec} / \mathrm{cm} 2 / \mathrm{str}] /$ Excitation light $\left[\mu \mathrm{W} / \mathrm{cm}^{2}\right] \times 10^{9}$ ) of 
corresponding organs. For controls, organs from two animals and for LNCs, organs from three animals at each time point were imaged. Epi-fluorescence color threshold was set between $2.0 \mathrm{x}$ $10^{8}$ to $1.0 \times 10^{9}$ radiant efficiency for image analysis.

\section{Results and discussion}

\subsection{Characterization of LNCs}

In this study, three different sizes of LNCs $(50,90$ and $120 \mathrm{~nm})$ loaded with PTX or DiD were developed (Fig. 1). The particle size of three different sized LNCs (PTX or DiD loaded) was found to be very close to the desired targeted size (50, 90 and $120 \mathrm{~nm}$ ) with narrow particle size distribution (PDI <0.2) such as $50 \pm 2,90 \pm 2$ and $120 \pm 3 \mathrm{~nm}$ for LNCs-PTX and $50 \pm 2,90 \pm 3$ and $120 \pm 4 \mathrm{~nm}$ for LNCs-DiD, respectively (Fig. 1B and D). Alternatively, the zeta potential of the six LNC preparations were in the range of -5 to $-9 \mathrm{mV}$ (Fig. 1B). Cryo-SEM micrograph of LNCs-PTX-50 nm (Fig. 1C) revealed a uniform spherical morphology, but with an average particle size of $40 \mathrm{~nm}$ (measured by ImageJ), i.e. slightly less than the hydrodynamic diameter measured by DLS, which is expected in accordance with reported studies (Bhattacharjee, 2016). The encapsulation efficiency of PTX was $>98 \%$ of the theoretical drug loading when using up to $1.5 \%$ (w/w of Labrafac) for all three sizes of LNCs (Fig. 1E). However, when increasing the drug loading above $1.5 \%$ (w/w of Labrafac), the encapsulation efficiency dropped to approximately $60 \%$. We speculate that this may be due to the solubility limit of PTX in Labrafac. All three LNCs-PTX formulations (50, 90 and $120 \mathrm{~nm}$ ) prepared with a theoretical loading of less than $1.5 \%, w / w$ of Labrafac, were stable without significant changes in their particle size/distribution (data not shown) and drug loading capacity during storage at $4{ }^{\circ} \mathrm{C}$ for more than 2 months (Fig. 1F). However, LNCs formulations with a theoretical loading of $1.5 \%$ (w/w of Labrafac) showed a storage stability of only one week at $4{ }^{\circ} \mathrm{C}$ (due to expulsion of PTX from LNCs; data not shown). 
Similarly, LNCs-DiD formulations of different size were found to be stable for 2 months (time period studied) at $4{ }^{\circ} \mathrm{C}$ without significant change in the particle size and fluorescence intensity of $\mathrm{DiD}$ (data not shown).

\subsection{Release of PTX from LNCs}

Fig. $1 \mathrm{G}, \mathrm{H}$ show release profiles for PTX from the three LNCs formulations at $37{ }^{\circ} \mathrm{C}$, at $\mathrm{pH} 5.0$ and 7.4. All three formulations showed similar release profiles, an initial rapid release of approximately $12 \%$ during the first $12 \mathrm{hr}$, followed by slow release for the rest of the incubation period of $72 \mathrm{hr}$, both at $\mathrm{pH} 5.0$ and $\mathrm{pH}$ 7.4. Moreover, we did not see any change in the particle size/distribution of LNCs in PBS of $\mathrm{pH} 5.0$ and $\mathrm{pH} 7.4$ (data not shown). Tween 80 (0.1\%, v/v) was used in the release study at $37^{\circ} \mathrm{C}$ (see section 2.9) to enhance solubility of released PTX in the aqueous PBS medium (Garcion et al., 2006; Lollo et al., 2018). Note that no release of drug from LNCs-PTX formulation was observed at $4{ }^{\circ} \mathrm{C}$ confirming their storage stability at this temperature.

\subsection{LNCs uptake by breast cancer cells}

The uptake of LNCs-DiD and LNCs-PTX by breast cancer cells was studied by flow cytometry, fluorescence microscopy and HPLC, respectively since LNCs which are not internalized by cells can easily be washed away (see below). As shown in Fig. 2A, the uptake of three different sized LNCs measured by flow cytometry was found to increase with increase in particle size (data shown for MDA-MB-468 cells). LNCs of $50 \mathrm{~nm}$ showed the lowest uptake (90 nm exhibited 1.5fold and $120 \mathrm{~nm}$ exhibited 2.2-fold increase compared to $50 \mathrm{~nm}$ ). However, the cytotoxicity data (described in section 3.5) revealed that irrespective of their size, LNCs-PTX particles induce a similar toxicity in all three breast cancer cell lines studied in vitro. We decided to use $90 \mathrm{~nm}$ LNCs for further studies. Fig. 2B shows representative fluorescence images for LNCs-DiD 
endocytosed by the three breast cancer cell lines. In order to quantify the accumulation or association of LNCs with the three cell lines, LNCs-DiD $(300 \mu \mathrm{g} / \mathrm{mL})$ were incubated with the cell lines for different time intervals, the cells were washed, and the fluorescence intensity of the cells was measured by flow cytometry. A set of control wells was maintained at $4{ }^{\circ} \mathrm{C}$ to check for energy independent uptake or cell surface association. The results reflect a faster internalization of LNCs-DiD particles by the MDA-MB-468 cell line, compared to the other two cell lines. Moreover, there are only negligible amounts of particles associated with the cells after washing and incubation at $4{ }^{\circ} \mathrm{C}$ (published data)(Szwed et al., 2020). Previous reports proved the uptake of NiR loaded LNCs in C6 glioma cells (Lacoeuille et al., 2007a) and intestinal epithelial Caco 2 cells (Roger et al., 2009) in a similar manner.

The accumulation of LNCs-PTX within the three cell lines was determined by the HPLC method. After $1.5 \mathrm{hr}$, free or LNC-bound PTX was clearly detectable in all three cell lines, and the levels were not further increased by prolonging the incubation to $3 \mathrm{hr}$ (Fig. 2C). The rate of uptake is, however, cell-type dependent, with MDA-MB-468 cells exhibiting a significantly higher uptake than the other two cell lines following $3 \mathrm{hr}$ incubation (approximately 3 -fold for PTX; and 25-40-fold MDA-MB-231 and MCF-7. The uptake of PTX is much higher (approximately 7.5-fold after $3 \mathrm{hr}$ of incubation) with LNCs-PTX than with free PTX. In contrast, we could not observe any difference between the accumulation of free PTX and LNCs-PTX in MCF-7 and MDA-MB-231 cells. Even though the uptake of LNCs-PTX was much higher in MDA-MB-468 cells, the LNCs-PTX formulation did not produce a higher cytotoxicity than free PTX. We do not have an obvious explanation to this, but the rate of PTX release from the particles inside the cellular environment could be a limiting factor. 


\subsection{LNCs-PTX induce cytotoxicity in breast cancer cells}

$\left[{ }^{3} \mathrm{H}\right]$ Thymidine incorporation assay was performed to measure the effect of PTX or LNCs-PTX on cell proliferation. Free PTX and LNCs-PTX were incubated with cells for $24 \mathrm{hr}$ using PTX concentrations of 0, 2, 4, 6 and $8 \mathrm{nM}$. As shown in Fig. 3A, PTX or LNCs-PTX significantly inhibited the proliferation of cells in a dose dependent manner. The $\mathrm{IC}_{50}$ values are approximately $2.1 \mathrm{nM}, 4.9 \mathrm{nM}$ and $3.8 \mathrm{nM}$ for MCF-7, MDA-MB-231 and MDA-MB-468 cells, respectively. The free drug and the drug encapsulated particles did not show any significant difference in the pattern of inhibition.

The cytotoxic effects of LNCs-PTX on the three breast cancer cell lines were also measured using the MTT assay. The particles as well as free drug were incubated with the cells for 24, 48 and $72 \mathrm{hr}$. LNCs-PTX were incubated with cells at equivalent concentrations of free PTX, which ranges from $1.56 \mathrm{nM}$ to $50 \mathrm{nM}$. The MTT assay measures the metabolic activity of the cells and the curves shown following incubation of cells for $24 \mathrm{hr}$ (Fig. 3B) are quite different from the $\left[{ }^{3} \mathrm{H}\right]$ thymidine incorporation assay measuring cell proliferation (Fig. 3A). The toxicity patterns obtained using the MTT test following incubation for $48 \mathrm{hr}$ (Fig. 3C) and $72 \mathrm{hr}$ (Fig. 3D) demonstrated increased toxicity in a dose and time dependent manner. IC $_{50}$ values for LNCsPTX-90 nm were $6.7 \mathrm{nM}, 7 \mathrm{nM}$ and $4.6 \mathrm{nM}$ for MCF-7, MDA-MB-231 and MDA-MB-468, respectively, which is similar to that obtained for the free PTX after $72 \mathrm{hr}$ of incubation (Fig. 3D). When comparing results from the two methods used to assess cytotoxicity, it can be concluded that the immediate action of PTX, to arrest the cell proliferation, is relatively more prominent in MCF-7 cells whereas with longer incubations and using the MTT test, MDA-MB468 cells seem to be most sensitive compared to the other two cell lines. 
Previous reports regarding the cytotoxicity of LNCs-PTX towards C6 glioma cells showed that PTX when encapsulated within LNCs were 40-fold more effective than the free drug after an incubation period of $96 \mathrm{hr}$ (Lacoeuille et al., 2007a). However, we did not observe such an improved pattern in cytotoxicity compared to free PTX in any of the breast cancer cell lines studied, and our data do not show any effect of varying the size of our LNCs-PTX in the size range 50-120 nm. The in vivo anti-tumor effect of the LNCs-encapsulated drug is, however, expected to be better than the free drug following intravenous injection as reported in an efficacy study of PTX-loaded LNCs against NCI-H460 lung carcinoma model in mice (Hureaux et al., 2010).

\subsection{Mechanisms of cellular uptake of LNCs and induction of apoptosis by LNCs-PTX}

We have previously shown that LNCs loaded with DiD are endocytosed and transported to lysosomes, and that incubation of cells with high concentrations of LNCs can affect protein synthesis, induce stress reactions and affect lysosomal $\mathrm{pH}$ in a reversible manner (Szwed et al., 2020). This suggest that although these particles are stable in solution (Fig. 1F) and similar LNCs have been found to be transcytosed in CaCo cells (Roger et al., 2017), they may to some extent be hydrolyzed after uptake in cells. This process is likely to be important for drug release, and to understand the toxic mechanism of the drug loaded particles we have here investigated the mechanisms of endocytosis in cells by using LNCs-DID and flow cytometry. The uptake has been measured using particles with a diameter of $90 \mathrm{~nm}$, a size that would permit uptake by most endocytic mechanisms.

Dynamin is a large GTPase involved in pinching off of vesicles from clathrin-coated pits, from caveolae, by FEME (fast endophilin-mediated endocytosis), by RhoA-dependent uptake as well as by macropinocytosis (Fig. 4B) from circular ruffles (Sandvig et al., 2018; Thottacherry et 
al., 2019), and there are a number of drugs targeting this GTPase. However, they can be toxic, have side-effects and are inhibited by serum (McCluskey et al., 2013), so in order to investigate whether dynamin is required for uptake of LNCs, we used a HeLa cell line with inducible expression of a dominant negative mutant of dynamin. Upon removal of tetracycline to obtain expression of mutant dynamin, transferrin-endocytosis was found to be reduced by more than $90 \%$ (during a 2 min incubation with transferrin at $37^{\circ} \mathrm{C}$, data not shown), and as demonstrated in Fig. 4C, the uptake of LNCs was actually increased. It has been shown earlier that expression of the dominant negative dynamin mutant can increase fluid phase uptake by other endocytic mechanisms (Damke et al., 1995; Damke et al., 1994), but our results clearly show that dynamin activity and for instance clathrin-dependent uptake are not required for endocytosis of LNCs.

Since caveolae in general seem to pinch off at a very slow rate (Hommelgaard et al., 2005) and have a diameter of 50-80 nm (Lamaze et al., 2017), one would not expect these structures to be important for uptake of LNCs-DiD-90 nms. In agreement with this assumption is the apparent lack of effect of genistein, which inhibits tyrosine kinases, and can inhibit uptake from caveolae (Pelkmans et al., 2002). It should however be noted that this drug is not exclusively affecting uptake from caveolae, it will inhibit clathrin-dependent uptake of growth factors such as EGF that needs the tyrosine kinase activity of its receptor to accumulate in clathrin-coated pits (Lamaze et al., 1993), and it might therefore also inhibit growth factor induced ruffling and macropinocytosis. Extraction of cholesterol from cell membranes by addition of methyl- $\beta$-cyclodextrin will ruin caveolar structures and an effect of this drug on uptake has often been used as evidence for involvement of caveolae. However, most, if not all endocytic processes are dependent on cholesterol (McCluskey et al., 2013), and as expected, 
treatment of all the three cell lines with methyl- $\beta$-cyclodextrin reduced the uptake of LNCs, although to a different extent.

One of the processes known to require cholesterol is macropinocytosis; a reduction of cholesterol will inhibit recruitment of Rac to the membrane (Grimmer et al., 2002), and block formation of macropinosomes. In agreement with the idea that macropinocytosis is important for uptake of LNCs is the finding that EIPA, an amiloride derivative, a drug that inhibits $\mathrm{Na}^{+} / \mathrm{H}^{+}$ exchange and reduces recruitment of Rac (Koivusalo et al., 2010), also inhibits endocytosis of LNCs, although most strongly in MCF-7 and MDA-MB-468 cells. Latranculin B treatment of cells is known to interfere with actin filament formation (Wakatsuki et al., 2001) and is expected to interfere with several different forms of endocytosis, among them uptake by macropinocytosis. It can however be difficult to obtain a sufficiently strong effect on actin filaments to get a substantial effect on endocytosis, but some reduction of LNCs uptake was obtained, the best effect was obtained in MCF-7 and MDA-MB-468, similarly to what was found for EIPAtreatment. The small GTPase Cdc42 has been reported to be involved both in the Cdc42/GRAF1dependent CLIC (clathrin-independent carriers)/GEEC (glycosylphosphatidylinositol-anchored protein enriched endosomal compartment) pathway (Thottacherry et al., 2019) and in macropinocytosis (Koivusalo et al., 2010) as well as in FEME, which is not required for LNCs uptake since it is dynamin-dependent. The inhibition seen after treatment with the Cdc42inhibitor ML141 (Hak et al., 2018), does not differentiate between these pathways, both might be involved. The GEEC pathway can be responsible for uptake of a large fraction of fluid in cells, but formation of macropinosomes gives rise to vesicles with a large volume to membrane ratio, and even a low extent of ruffling and macropinocytosis may therefore lead to uptake of a substantial fraction of LNCs. It cannot be excluded that interaction of the particles with cellular 
membranes might induce macropinocytosis. We have earlier found that in contrast to uptake of ricin, endocytosis of ricin coupled to Q-dots occurs mostly by a dynamin-dependent process (Iversen et al., 2012), and this might be due to crosslinking of surface molecules which may change signaling in cells (Imamura et al., 2011; Klokk et al., 2016). PI-3kinase signaling is known to be important both for macropinocytosis and for the Cdc42-dependent GEEC pathway (Thottacherry et al., 2019), and as shown in Fig. 4C, wortmannin, an inhibitor of this enzyme, actually gave the best inhibition of LNCs uptake in the three cell lines tested. In conclusion, the data shown indicate that dynamin-dependent processes are not required for uptake of LNCs, although we cannot exclude that they do contribute to some extent. More important for the uptake, seems to be the Cdc42/GRAF dependent endocytic mechanism as well as macropinocytosis.

To test the idea that internalization of LNCs is required for release of the cytotoxic drug paclitaxel, we incubated cells with LNCs in the absence and presence of different endocytosis inhibitors. Then, after $2 \mathrm{hr}$ incubation with the LNCs, both the particles and the inhibitors were removed by washing and the cells were incubated for $22 \mathrm{hr}$ in full medium before [3H]thymidine incorporation was measured. In agreement with the idea that endocytic uptake is required for release of PTX and induction of cytotoxicity in MCF-7 cells are the results shown in Fig. 4D. When endocytosis of LNCs was inhibited by the drugs described above, the effect of LNCs-PTX on cellular thymidine incorporation was reduced. Also, the effect of LNCs-PTX on Hela cells expressing mutant dynamin was increased, in agreement with the finding that uptake of particles is higher in cells expressing the dominant negative dynamin mutant in Fig. 4E. Thus, dynamindependent uptake mechanisms are clearly not required for induction of cytotoxicity. 
It has previously been described that PTX kills cells by induction of apoptosis (Au et al., 1999). To investigate whether LNCs-PTX would also kill cells by the same mechanism, we assessed hallmarks of apoptosis induction, i.e. activation of caspase- 3 and cleavage of the caspase-substrate PARP, in cells treated with LNCs-PTX. As shown in Fig. 5, treatment with LNCs-PTX induced cleavage of PARP in all the three cell lines tested in a manner comparable to that induced by free PTX. Moreover, LNCs-PTX also induced cleavage of caspase-3 in MDAMB-231 and MDA-MB-468 cells. MCF-7 cells do not express caspase-3 (Jänicke, 2009). These data demonstrate that treatment with LNCs-PTX induce apoptosis. This conclusion is supported by microscopy (Fig. S1) showing that LNCs-PTX induced morphological changes such as cell shrinkage and membrane protrusions.

\subsection{Biodistribution studies}

It is important to perform biodistribution studies early in the testing of new NPs in order to avoid investing in developing NPs which show a very unfavorable biodistribution. There are many reports showing that only a minor fraction (less than 1\%) of the injected dose is ending up in tumors (Wilhelm et al., 2016), meaning that one can perform the initial biodistribution study in non-tumor-bearing animals as we have done in our study. All methods presently available for studying biodistribution and metabolism have their advantages and disadvantages and better methods are warranted (Skotland et al., 2014). It is popular to use IVIS ${ }^{\circledR}$ imaging to study the biodistribution of fluorescently labelled NPs. However, it is important that the fluorescent label is not added to the surface of NPs as this will change the surface properties and thus the biodistribution. In the present study we have encapsulated the fluorescent, hydrophobic marker DiD in LNCs. 
The biodistribution studies were performed to analyze the distribution of LNCs among various tissues in vivo after intravenous injection in mice. We performed an initial study with intravenous injection of LNCs-DiD-90 nm using two different doses (0.4 and $0.8 \mathrm{mg} / \mathrm{injection})$ and three mice for each time point. Whole body imaging with the fluorescent imaging system IVIS $^{\circledR}$ Spectrum, were performed 1 and $24 \mathrm{hr}$ after injection, before the animals were sacrificed and ex vivo images of liver, spleen, kidneys, lungs, heart, and colon were obtained using the IVIS ${ }^{\circledR}$ Spectrum (data not shown). Based on this initial study we decided to perform a similar study where $0.8 \mathrm{mg}$ LNCs-DiD-90 $\mathrm{nm}$ were injected, and the animals were sacrificed after 4, 24, and $48 \mathrm{hr}$. The images obtained of these organs at the three time points are shown in Fig. 6A-C and the quantification of the fluorescence is shown in Fig. 6D-F. These data show similarities to those reported for many other NPs (He et al., 2010; Skotland et al., 2010; Wilhelm et al., 2016) and demonstrate that the liver is taking up much more of the LNCs than the other organs. In contrast to the results referred to for other NPs, there is in our study a relatively low uptake in spleen and high signal in kidneys $4 \mathrm{hr}$ after injection.

To compare the decrease in fluorescence in the various organs following injection of LNCs, the fluorescence signals of organs not injected with LNCs were subtracted from the signals of organs receiving LNCs. Plotting of such data as a function of time after injection (Fig. S2) clearly shows that the decrease in fluorescence, which occurred most rapidly in liver and kidneys. It should be noted that the liver data shown in this figure are divided by a factor of 5 in order to be able to show these curves with a similar scale on the y-axis.

The pharmacokinetics of LNCs in rat blood has been studied for up to $12 \mathrm{hr}$ following injection of particles containing ${ }^{14} \mathrm{C}$-labeled triglycerides or phosphatidylcholine (Lacoeuille et al., 2007b) or by measuring the blood concentration of PTX following injection of PTX-loaded 
LNCs (Groo et al., 2015). These studies show a rather similar elimination curve for free PTX and LNCs-encapsulated PTX during the first $12 \mathrm{hr}$ after injection.

\section{Conclusions}

LNCs-PTX were developed and tuned to three sizes with hydrodynamic diameters of 50, 90 and $120 \mathrm{~nm}$. These LNCs were characterized and analyzed for their potential as drug nanocarriers for breast cancer treatment by using the three breast cancer cell lines MCF-7, MDA-MB-231 and MDA-MB-468. These lipid-based formulations effectively encapsulated the hydrophobic drug PTX with good encapsulation efficiency. The LNCs-PTX and LNCs-DiD formulations were stable when stored at $4{ }^{\circ} \mathrm{C}$ for at least 2 months. The three breast cancer cell lines studied endocytosed the LNC particles in a particle size- and cell-dependent manner. The in vitro cytotoxicity studies revealed that MDA-MB-468 cells were more sensitive to LNCs-PTX than the two other cell lines, which correlates with the cellular uptake of LNCs-PTX in these three cell lines. Studies with inhibitors of endocytic mechanisms indicate that the cellular uptake seems to be mainly via Cdc42/GRAF-dependent endocytic mechanism as well as by micropinocytosis, whereas dynamin-dependent processes are not required. This study emphasizes the potential of PTX-loaded LNCs in the treatment of breast cancer. Encapsulation of various drugs combination targeting cancer cells and cancer stem cells, and its microenvironment, would be an interesting possibility to explore further (currently in progress). Although, we did not observe any large difference in the cytotoxicity of PTX, in free and LNC-encapsulated form, the relatively higher internalization of LNCs formulation, suggest a favorable therapeutic efficacy of LNCs formulation that should be further explored in preclinical models of breast cancer. 


\section{Acknowledgements}

The Oslo group acknowledge support from Inno Indigo (an EU and India joint project; number 261093), Research Council of Norway (Nano 2021; project numbers 228200 (NANOCAN) and 274574 (nano AUTOPHAGY), the Norwegian Cancer Society, and the South Eastern Norway Regional Health Authority. The Indian group acknowledge support from Department of Science and Technology, (Nanomission, project number SR/NM/-NS-1364/2014), DST-INNOINDIGO: (project number DST/IMRCD/INNO-INDIGO/NANOBREASTCO/2015), and the Department

of Biotechnology, (Project numbers BT/RLF/Reentry/21/2013 and BT/PR14629/NNT/28/823/2015). The groups in Oslo thank Anne Grethe Myrann for technical assistance with in vitro studies. The core facilities for confocal microscopy and flow cytometry at Oslo University Hospital are acknowledged for providing access to equipment. also acknowledge the Department for Comparative Medicine, Oslo University Hospital for providing experimental animals and access to facilities and instrumentation.

\section{Competing interests}

The authors declare that they do not have any competing interests.

\section{Availability of data and materials}

All data generated or analyzed during this study are included in this published article and its additional file. 


\section{References}

Apfelthaler, C., Skoll, K., Ciola, R., Gabor, F., \& Wirth, M. (2018). A doxorubicin loaded colloidal delivery system for the intravesical therapy of non-muscle invasive bladder cancer using wheat germ agglutinin as targeter. European Journal of Pharmaceutics and Biopharmaceutics, 130, 177-184.

Au, J. L., Wientjes, M. G., Kumar, R. R., \& Li, D. (1999). Kinetics of hallmark biochemical changes in paclitaxel-induced apoptosis. AAPS PharmSci, 1(3), 7-14.

Bazak, R., Houri, M., El Achy, S., Kamel, S., \& Refaat, T. (2015). Cancer active targeting by nanoparticles: a comprehensive review of literature. Journal of cancer research and clinical oncology, 141(5), 769-784.

Bhattacharjee, S. (2016). DLS and zeta potential-what they are and what they are not? Journal of controlled release, 235, 337-351.

Cao, J., Wang, C., Guo, L., Xiao, Z., Liu, K., \& Yan, H. (2018). Co-administration of a charge-conversional dendrimer enhances antitumor efficacy of conventional chemotherapy. European Journal of Pharmaceutics and Biopharmaceutics, 127, 371-377.

Choi, H. S., Liu, W., Misra, P., Tanaka, E., Zimmer, J. P., Ipe, B. I., . . Frangioni, J. V. (2007). Renal clearance of quantum dots. Nature biotechnology, 25(10), 1165-1170.

Chowdhury, P., Nagesh, P. K., Hatami, E., Wagh, S., Dan, N., Tripathi, M. K., . . Chauhan, S. C. (2019). Tannic acid-inspired paclitaxel nanoparticles for enhanced anticancer effects in breast cancer cells. Journal of colloid and interface science, 535, 133-148.

Damke, H., Baba, T., Van Der Bliek, A. M., \& Schmid, S. L. (1995). Clathrin-independent pinocytosis is induced in cells overexpressing a temperature-sensitive mutant of dynamin. The Journal of cell biology, 131(1), 69-80.

Damke, H., Baba, T., Warnock, D. E., \& Schmid, S. L. (1994). Induction of mutant dynamin specifically blocks endocytic coated vesicle formation. The Journal of cell biology, 127(4), 915-934.

Garcion, E., Lamprecht, A., Heurtault, B., Paillard, A., Aubert-Pouessel, A., Denizot, B., . . Benoît, J.-P. (2006). A new generation of anticancer, drug-loaded, colloidal vectors reverses multidrug resistance in glioma and reduces tumor progression in rats. Molecular cancer therapeutics, 5(7), 1710-1722.

Grimmer, S., van Deurs, B., \& Sandvig, K. (2002). Membrane ruffling and macropinocytosis in A431 cells require cholesterol. Journal of cell science, 115(14), 2953-2962.

Groo, A.-C., Bossiere, M., Trichard, L., Legras, P., Benoît, J.-P., \& Lagarce, F. (2015). In vivo evaluation of paclitaxel-loaded lipid nanocapsules after intravenous and oral administration on resistant tumor. Nanomedicine, 10(4), 589-601.

Guan, S., Zhang, Q., Bao, J., Duan, T., Hu, R., Czech, T., \& Tang, J. (2020). Phosphatidylserine targeting peptide-functionalized $\mathrm{pH}$ sensitive mixed micelles for enhanced anti-tumor drug delivery. European Journal of Pharmaceutics and Biopharmaceutics, 147, 87-101.

Guillen, J. (2012). FELASA guidelines and recommendations. Journal of the American association for laboratory animal science, 51(3), 311-321.

Hak, L. C. W., Khan, S., Di Meglio, I., Law, A.-L., Häsler, S. L.-A., Quintaneiro, L. M., . . Boucrot, E. (2018). FBP17 and CIP4 recruit SHIP2 and lamellipodin to prime the plasma membrane for fast endophilin-mediated endocytosis. Nature cell biology, 20(9), 1023-1031.

He, C., Hu, Y., Yin, L., Tang, C., \& Yin, C. (2010). Effects of particle size and surface charge on cellular uptake and biodistribution of polymeric nanoparticles. Biomaterials, 31(13), 3657-3666.

Heurtault, B., Saulnier, P., Pech, B., Proust, J.-E., \& Benoit, J.-P. (2002). A novel phase inversion-based process for the preparation of lipid nanocarriers. Pharmaceutical research, 19(6), 875-880. 
Holliday, D. L., \& Speirs, V. (2011). Choosing the right cell line for breast cancer research. Breast cancer research, 13(4), 1-7.

Hommelgaard, A. M., Roepstorff, K., Vilhardt, F., Torgersen, M. L., Sandvig, K., \& van Deurs, B. (2005). Caveolae: stable membrane domains with a potential for internalization. Traffic, 6(9), 720-724.

Hureaux, J., Lagarce, F., Gagnadoux, F., Rousselet, M.-C., Moal, V., Urban, T., \& Benoit, J.-P. (2010). Toxicological study and efficacy of blank and paclitaxel-loaded lipid nanocapsules after iv administration in mice. Pharmaceutical research, 27(3), 421-430.

Hureaux, J., Lagarce, F., Gagnadoux, F., Vecellio, L., Clavreul, A., Roger, E., . . Benoit, J.-P. (2009). Lipid nanocapsules: ready-to-use nanovectors for the aerosol delivery of paclitaxel. European Journal of Pharmaceutics and Biopharmaceutics, 73(2), 239-246.

Huynh, N. T., Passirani, C., Saulnier, P., \& Benoît, J.-P. (2009). Lipid nanocapsules: a new platform for nanomedicine. International journal of pharmaceutics, 379(2), 201-209.

Imamura, J., Suzuki, Y., Gonda, K., Roy, C. N., Gatanaga, H., Ohuchi, N., \& Higuchi, H. (2011). Single particle tracking confirms that multivalent Tat protein transduction domain-induced heparan sulfate proteoglycan cross-linkage activates Rac1 for internalization. Journal of Biological Chemistry, 286(12), 10581-10592.

Iversen, T. G., Frerker, N., \& Sandvig, K. (2012). Uptake of ricinB-quantum dot nanoparticles by a macropinocytosis-like mechanism. Journal of nanobiotechnology, 10(1), 1-11.

Jänicke, R. U. (2009). MCF-7 breast carcinoma cells do not express caspase-3. Breast cancer research and treatment, 117(1), 219-221.

Klokk, T. I., Kavaliauskiene, S., \& Sandvig, K. (2016). Cross-linking of glycosphingolipids at the plasma membrane: consequences for intracellular signaling and traffic. Cellular and molecular life sciences, 73(6), 1301-1316.

Koivusalo, M., Welch, C., Hayashi, H., Scott, C. C., Kim, M., Alexander, T., . . . Grinstein, S. (2010). Amiloride inhibits macropinocytosis by lowering submembranous $\mathrm{pH}$ and preventing Rac1 and Cdc42 signaling. Journal of Cell Biology, 188(4), 547-563.

Lacoeuille, F., Garcion, E., Benoit, J.-P., \& Lamprecht, A. (2007a). Lipid nanocapsules for intracellular drug delivery of anticancer drugs. Journal of nanoscience and nanotechnology, 7(12), 4612-4617.

Lacoeuille, F., Hindré, F., Moal, F., Roux, J., Passirani, C., Couturier, O., . . Benoit, J.-P. (2007b). In vivo evaluation of lipid nanocapsules as a promising colloidal carrier for paclitaxel. International journal of pharmaceutics, 344(1-2), 143-149.

Lamaze, C., Baba, T., Redelmeier, T. E., \& Schmid, S. L. (1993). Recruitment of epidermal growth factor and transferrin receptors into coated pits in vitro: differing biochemical requirements. Molecular biology of the cell, 4(7), 715-727.

Lamaze, C., Tardif, N., Dewulf, M., Vassilopoulos, S., \& Blouin, C. M. (2017). The caveolae dress code: structure and signaling. Current opinion in cell biology, 47, 117-125.

Lamprecht, A., Bouligand, Y., \& Benoit, J.-P. (2002). New lipid nanocapsules exhibit sustained release properties for amiodarone. Journal of controlled release, 84(1-2), 59-68.

Logan, K., Foglietta, F., Nesbitt, H., Sheng, Y., McKaig, T., Kamila, S., . . McHale, A. P. (2019). Targeted chemo-sonodynamic therapy treatment of breast tumours using ultrasound responsive microbubbles loaded with paclitaxel, doxorubicin and Rose Bengal. European Journal of Pharmaceutics and Biopharmaceutics, 139, 224-231.

Lollo, G., Ullio-Gamboa, G., Fuentes, E., Matha, K., Lautram, N., \& Benoit, J.-P. (2018). In vitro anti-cancer activity and pharmacokinetic evaluation of curcumin-loaded lipid nanocapsules. Materials Science and Engineering: C, 91, 859-867. 
Lollo, G., Vincent, M., Ullio-Gamboa, G., Lemaire, L., Franconi, F., Couez, D., \& Benoit, J.-P. (2015). Development of multifunctional lipid nanocapsules for the co-delivery of paclitaxel and CpGODN in the treatment of glioblastoma. International journal of pharmaceutics, 495(2), 972-980.

Ma, P., \& Mumper, R. J. (2013). Paclitaxel nano-delivery systems: a comprehensive review. Journal of nanomedicine \& nanotechnology, 4(2), 1000164.

Matsumura, Y., \& Maeda, H. (1986). A new concept for macromolecular therapeutics in cancer chemotherapy: mechanism of tumoritropic accumulation of proteins and the antitumor agent smancs. Cancer research, 46(12 Part 1), 6387-6392.

Mattu, C., Pabari, R., Boffito, M., Sartori, S., Ciardelli, G., \& Ramtoola, Z. (2013). Comparative evaluation of novel biodegradable nanoparticles for the drug targeting to breast cancer cells. European Journal of Pharmaceutics and Biopharmaceutics, 85(3), 463-472.

McCluskey, A., Daniel, J. A., Hadzic, G., Chau, N., Clayton, E. L., Mariana, A., . . Quan, A. (2013). Building a better dynasore: the dyngo compounds potently inhibit dynamin and endocytosis. Traffic, 14(12), 1272-1289.

Pelkmans, L., Püntener, D., \& Helenius, A. (2002). Local actin polymerization and dynamin recruitment in SV40-induced internalization of caveolae. science, 296(5567), 535-539.

Peng, F., Li, R., Zhang, F., Qin, L., Ling, G., \& Zhang, P. (2020). Potential drug delivery nanosystems for improving tumor penetration. European Journal of Pharmaceutics and Biopharmaceutics.

Petrelli, F., Borgonovo, K., \& Barni, S. (2010). Targeted delivery for breast cancer therapy: the history of nanoparticle-albumin-bound paclitaxel. Expert opinion on pharmacotherapy, 11(8), 1413-1432.

Poli, G., Cantini, G., Armignacco, R., Fucci, R., Santi, R., Canu, L., ... Luconi, M. (2016). Metformin as a new anti-cancer drug in adrenocortical carcinoma. Oncotarget, 7(31), 49636.

Prabhakar, U., Maeda, H., Jain, R. K., Sevick-Muraca, E. M., Zamboni, W., Farokhzad, O. C., ... Blakey, D. C. (2013). Challenges and key considerations of the enhanced permeability and retention effect for nanomedicine drug delivery in oncology: AACR.

Roger, E., Gimel, J.-C., Bensley, C., Klymchenko, A. S., \& Benoit, J.-P. (2017). Lipid nanocapsules maintain full integrity after crossing a human intestinal epithelium model. Journal of controlled release, 253, 11-18.

Roger, E., Lagarce, F., Garcion, E., \& Benoit, J.-P. (2009). Lipid nanocarriers improve paclitaxel transport throughout human intestinal epithelial cells by using vesicle-mediated transcytosis. Journal of controlled release, 140(2), 174-181.

Roger, E., Lagarce, F., Garcion, E., \& Benoit, J.-P. (2010). Reciprocal competition between lipid nanocapsules and P-gp for paclitaxel transport across Caco-2 cells. European Journal of Pharmaceutical Sciences, 40(5), 422-429.

Sandvig, K., Kavaliauskiene, S., \& Skotland, T. (2018). Clathrin-independent endocytosis: an increasing degree of complexity. Histochemistry and cell biology, 150(2), 107-118.

Shi, J., Kantoff, P. W., Wooster, R., \& Farokhzad, O. C. (2017). Cancer nanomedicine: progress, challenges and opportunities. Nature Reviews Cancer, 17(1), 20.

Skotland, T., Iversen, T.-G., \& Sandvig, K. (2014). Development of nanoparticles for clinical use. Nanomedicine, 9(9), 1295-1299.

Skotland, T., Iversen, T.-G., \& Sandvig, K. (2010). New metal-based nanoparticles for intravenous use: requirements for clinical success with focus on medical imaging. Nanomedicine: Nanotechnology, Biology and Medicine, 6(6), 730-737.

Szwed, M., Torgersen, M. L., Kumari, R. V., Yadava, S. K., Pust, S., Iversen, T. G., . . Sandvig, K. (2020). Biological response and cytotoxicity induced by lipid nanocapsules. Journal of nanobiotechnology, 18(1), 1-19. 
Thottacherry, J. J., Sathe, M., Prabhakara, C., \& Mayor, S. (2019). Spoiled for choice: diverse endocytic pathways function at the cell surface. Annual review of cell and developmental biology, 35, 5584.

Torchilin, V. P. (2014). Multifunctional, stimuli-sensitive nanoparticulate systems for drug delivery. Nature reviews Drug discovery, 13(11), 813-827.

Tran, S., DeGiovanni, P.-J., Piel, B., \& Rai, P. (2017). Cancer nanomedicine: a review of recent success in drug delivery. Clinical and translational medicine, 6(1), 44.

Vittorio, O., Le Grand, M., Makharza, S. A., Curcio, M., Tucci, P., lemma, F., . . C Cirillo, G. (2018). Doxorubicin synergism and resistance reversal in human neuroblastoma BE (2) C cell lines: An in vitro study with dextran-catechin nanohybrids. European Journal of Pharmaceutics and Biopharmaceutics, 122, 176-185.

Wakatsuki, T., Schwab, B., Thompson, N. C., \& Elson, E. L. (2001). Effects of cytochalasin D and latrunculin B on mechanical properties of cells. Journal of cell science, 114(5), 1025-1036.

Wilhelm, S., Tavares, A. J., Dai, Q., Ohta, S., Audet, J., Dvorak, H. F., \& Chan, W. C. (2016). Analysis of nanoparticle delivery to tumours. Nature reviews materials, 1(5), 1-12.

Xie, J., Yang, Z., Zhou, C., Zhu, J., Lee, R. J., \& Teng, L. (2016). Nanotechnology for the delivery of phytochemicals in cancer therapy. Biotechnology advances, 34(4), 343-353.

Yadava, S. K., Basu, S. M., Chauhan, M., Sharma, K., Pradhan, A., Remya, V., \& Giri, J. (2020). Low temperature, easy scaling upmethod for development of smart nanostructure hybrid lipid capsulesfor drug delivery application. Colloids and Surfaces B: Biointerfaces, 110927.

Zhai, J., Luwor, R. B., Ahmed, N., Escalona, R., Tan, F. H., Fong, C., ... Tran, N. (2018). Paclitaxel-loaded self-assembled lipid nanoparticles as targeted drug delivery systems for the treatment of aggressive ovarian cancer. ACS applied materials \& interfaces, 10(30), 25174-25185. 


\section{Conflict of interest}

The authors declare that they do not have any competing interests. 


\section{Authors' contributions}

Remya Valsalakumari, Sunil Kumar Yadava, Marzena Szwed: Performed in vitro experiments, prepared figures and contributed for drafting the manuscript. They are equally contributed. Abhilash D. Pandya: Performed, analyzed and prepared figures for the biodistribution study. Gunhild Mari Mælandsmo: planned and supervised the biodistribution study. Maria Lyngaas Torgersen: supervised the immunoblotting analyses. Tore-Geir Iversen: contributed to the conception of the study and the in vitro analyses. Tore Skotland: planned the project, supervised the biological studies and the preparation of the manuscript. Kirsten Sandvig (Corresponding author): planned the project, supervised the biological studies and the preparation of the manuscript. Jyotsnendu Giri (Corresponding author): planned the project, supervised the studies in Hyderabad and the preparation of the manuscript.

All authors revised the draft. All authors read and approved the final manuscript. 


\section{Figure legends}

Fig. 1. Physicochemical properties of LNCs. (A) Schematic representation of the LNC. (B) Particles size, polydispersity index (PDI) and zeta potential of LNCs preparations used in this study. (C) Cryo-SEM micrographs of LNCs-PTX-50 nm. (D) Particle size distribution of LNCs (50, 90 and $120 \mathrm{~nm}$ ) loaded with PTX or DiD. (E) Percent encapsulation efficiency of PTX with different theoretical loading (with respect to Labrafac; w/w). (F) Stability of LNCs-PTX (50, 90, $120 \mathrm{~nm}$ ) stored for two months at $4{ }^{\circ} \mathrm{C}$. Stability was determined as \% of encapsulated PTX. (G, H) Release profile of PTX from LNCs-PTX at pH 5.0 and $\mathrm{pH} 7.4$, respectively, in the presence of Tween 80 .

Fig. 2. Uptake of LNCs-DiD in breast cancer cells. (A) Comparative accumulation of different sized LNCs-DiD (50, 90 and $120 \mathrm{~nm}$ ) in MDA-MB-468 cells. Cells were seeded and treated with $300 \mu \mathrm{g} / \mathrm{ml}$ of different sized LNCs-DiD for $3 \mathrm{~h}$ at $37{ }^{\circ} \mathrm{C}$ followed by flow cytometry analysis. Values are mean fluorescence intensity of 10,000 cells counted; $* * p<0.01, * p<0.05$. (B) Fluorescence microscopic images demonstrating uptake of LNCs-DiD-90 nm by MCF-7, MDAMB-231 and MDA-MB-468 cells. Cells were seeded and treated with LNCs-DiD-90 nm (300 $\mu \mathrm{g} / \mathrm{mL}$ ) for $3 \mathrm{~h}$ at $37{ }^{\circ} \mathrm{C}$. Nuclei was counterstained with Hoechst followed by fluorescence microscopy analysis. Images were captured at $20 \mathrm{X}$ and scale bar represents $10 \mu \mathrm{m}$. (C) Comparative accumulation after 1.5 and $3 \mathrm{~h}$ incubation with PTX or LNCs-PTX-90 nm in MCF7, MDA-MB-231 and MDA-MB-468 cells (treated with equivalent concentration of $25 \mu \mathrm{M}$ PTX); PTX quantified by HPLC. Values are mean $\pm \mathrm{SD} ; * * * p<0.001, * p<0.05$.

Fig. 3. Cytotoxic effects of free PTX and LNCs-PTX (50, 90, $120 \mathrm{~nm})$ on MCF-7, MDAMB-231 and MDA-MB-468 cells. (A) Cell proliferation measured as $\left[{ }^{3} \mathrm{H}\right]$ thymidine incorporation after $24 \mathrm{~h}$ incubation with the various LNCs. (B) Cell viability estimated by using the MTT assay after $24 \mathrm{~h}$ incubation. (C) Cell viability estimated by using the MTT assay after $48 \mathrm{~h}$ incubation. (D) Cell viability estimated by using the MTT assay after $72 \mathrm{~h}$ incubation. Data represented as mean $\pm \mathrm{SEM}$.

Fig. 4. Endocytic mechanisms involved in the uptake of LNCs. (A) List of the pharmacological inhibitors used to study endocytosis of LNCs. (B) Schematic overview of 
various types of endocytosis. (C) Uptake of LNCs-DiD-90 nm by MCF-7, MDA-MB-231 and MDA-MB-468 cells. Cells were pretreated with the inhibitors for $30 \mathrm{~min}$ at $37{ }^{\circ} \mathrm{C}$ using cell growth medium supplemented with $1 \%$ FCS. The cells were then incubated with $0.5 \mathrm{mg} / \mathrm{mL}$ LNCs-DiD-90 $\mathrm{nm}$ in the same medium for $2 \mathrm{~h}$ at $37^{\circ} \mathrm{C}$. Experiments were also performed using HeLa K44A cells which express a dominant negative mutant of dynamin in the absence of tetracycline. The fluorescence intensity was quantified by flow cytometry and data shown as mean \pm SEM $(n=3)$. The $p$ values were calculated by comparison of data obtained in control cells without inhibitors; *, $p<0.05$; **, $p<0.01$, ***, $p<0.001$. (D) Dose-dependent effects of LNCs-PTX-90 nm on proliferation ([ $\left.{ }^{3} \mathrm{H}\right]$ thymidine incorporation) in MCF-7 cells following treatment of cells with the inhibitors and LNCs, washing and incubation in full medium for $24 \mathrm{~h}$ as described in Methods. The graphs show mean $\pm \mathrm{SEM} ; \mathrm{n} \geq 3 ; *, p<0.05, * *, p<0.01$, *** $p<$ 0.001 for comparison of cells pre-incubated with different inhibitors of endocytosis. (E) Proliferation $\left(\left[{ }^{3} \mathrm{H}\right]\right.$ thymidine incorporation) of HeLa K44A cells following $24 \mathrm{~h}$ incubation with LNCs-PTX-90 nm. These cells are expressing normal dynamin in the presence of tetracycline and mutated dynamin in the absence of tetracycline. The data are shown as mean \pm SEM; $n=3$.

Fig. 5. LNCs-PTX particles induce apoptotic cell death. MCF-7, MDA-MB-231 and MDAMB-468 cells were treated with the indicated concentrations of LNCs, LNCs-PTX, or free PTX for $72 \mathrm{~h}$ and cell lysates were then prepared for immunoblotting. Detached cells were collected and included in the lysates, and equal amounts of proteins were loaded on the gel. The blots were probed with the indicated antibodies, and apoptosis is indicated by cleaved PARP (cl. PARP) and cleaved caspase-3 (cl. caspase-3).

Fig. 6. Biodistribution of LNCs-DiD-90 $\mathbf{~ m m}$ in mice. Organs were harvested at $4 \mathrm{~h}(\mathrm{~A}), 24 \mathrm{~h}$ (B) and $48 \mathrm{~h}$ (C) following injection of $0.8 \mathrm{mg}$ LNCs-DiD-90 nm; mice not receiving any injections were used as controls. The fluorecence was quantified in the various organs as described in Methods and are presented as total radiant efficiency $/ 10^{8}$ for liver, spleen, kidneys, lungs, heart and colon. The columns plotted are corresponding to the images shown for $4 \mathrm{~h}$ (D), $24 \mathrm{~h}(\mathrm{E})$ and $48 \mathrm{~h}(\mathrm{~F})$. Data are shown as mean $\pm \mathrm{SD}$ ( $n=2$ for control; $n=3$ for LNCs). 


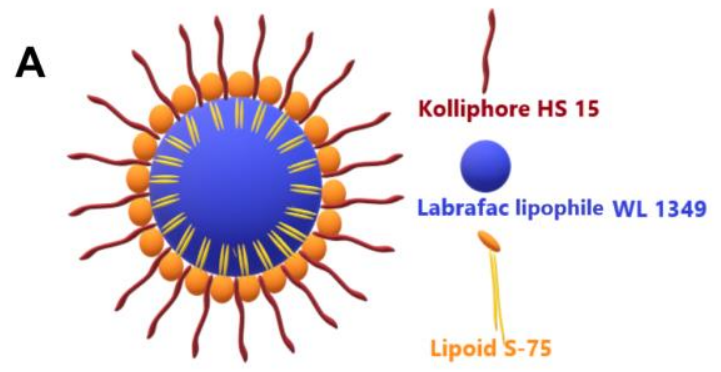

\begin{tabular}{lcccc}
\hline \multicolumn{1}{c}{ Batch Code } & $\begin{array}{c}\text { Particles size } \\
(\mathrm{nm})\end{array}$ & PDI & $\begin{array}{c}\zeta \text { - Potential } \\
(\mathrm{mV})\end{array}$ \\
\hline LNCs-PTX-50 $\mathrm{nm}$ & $50 \pm 2$ & $0.145 \pm 0.007$ & $-8 \pm 2$ \\
LNCs-PTX-90 $\mathrm{nm}$ & $90 \pm 2$ & $0.101 \pm 0.002$ & $-9 \pm 2$ \\
LNCs-PTX-120 nm & $120 \pm 3$ & $0.100 \pm 0.013$ & $-5 \pm 2$ \\
LNCs-DiD-50 $\mathrm{nm}$ & $50 \pm 2$ & $0.080 \pm 0.005$ & $-8 \pm 1$ \\
LNCs-DiD-90 $\mathrm{nm}$ & $90 \pm 3$ & $0.111 \pm 0.002$ & $-7 \pm 2$ \\
LNCs-DiD-120 nm & $120 \pm 4$ & $0.120 \pm 0.016$ & $-9 \pm 2$ \\
\hline
\end{tabular}

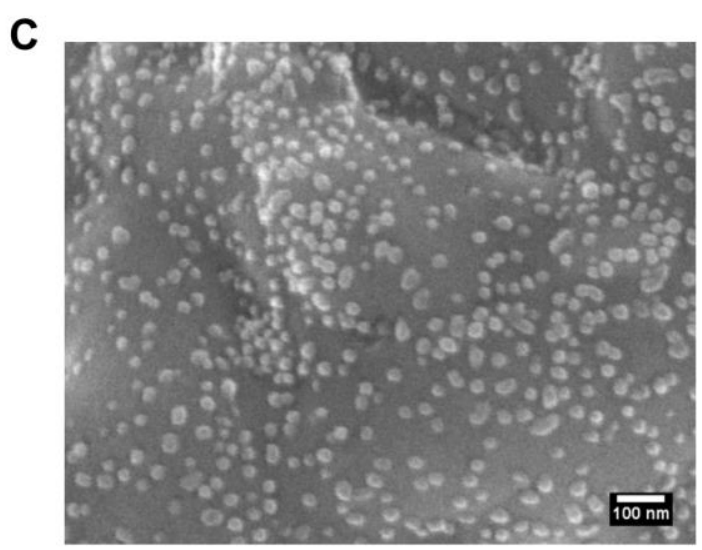

D

E

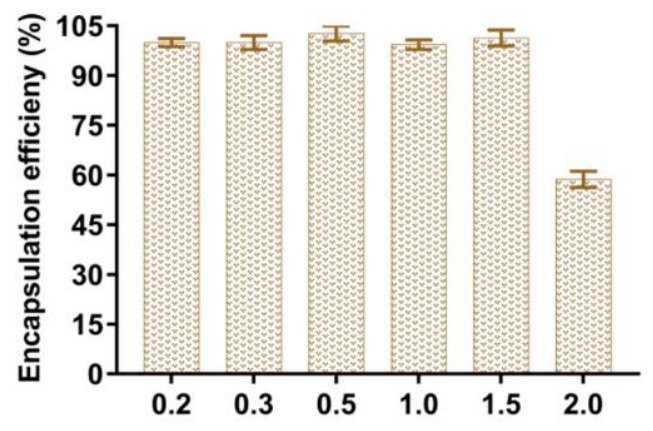

Theoretical loading of PTX (\%, w/w of Labrafac)

G

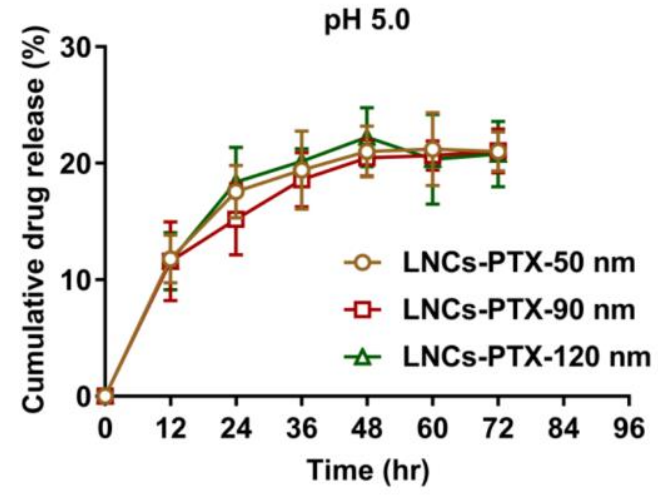

F

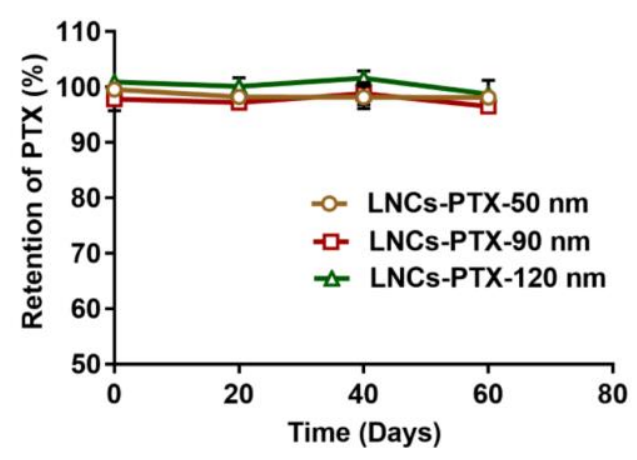

H

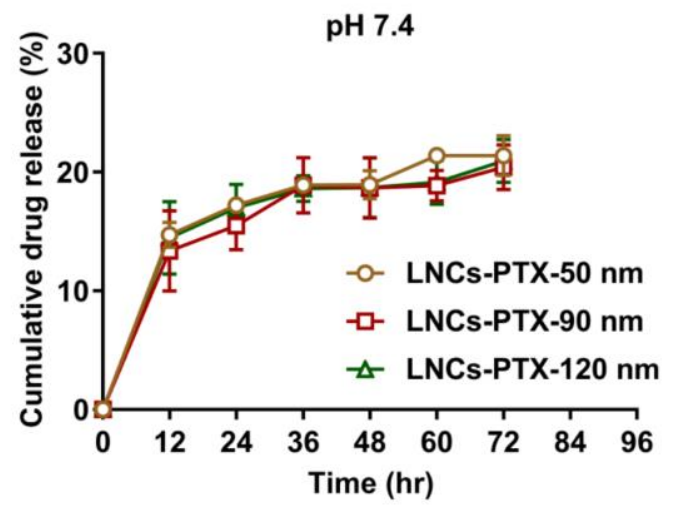

Fig. 1 
A

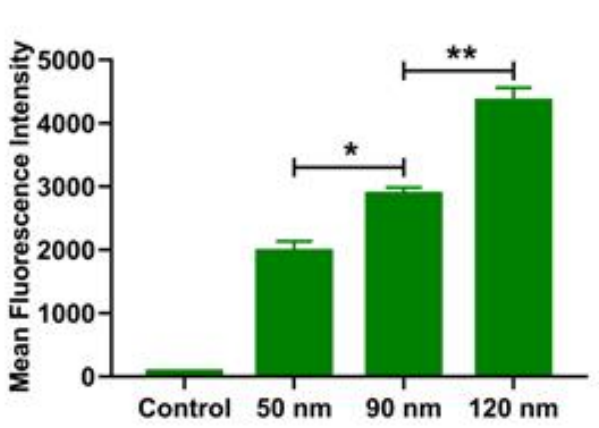

B
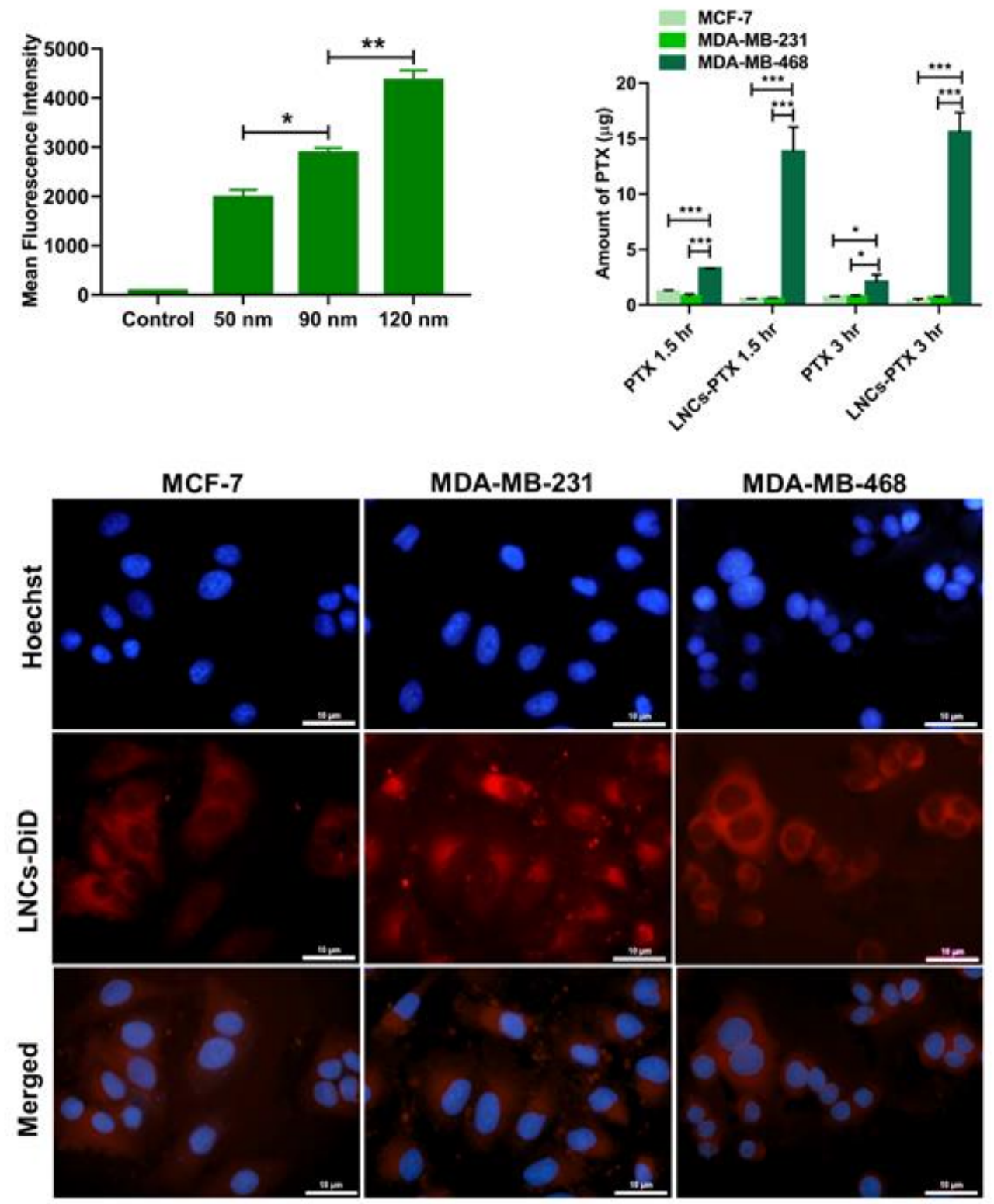

Fig. 2

Fig. 2 

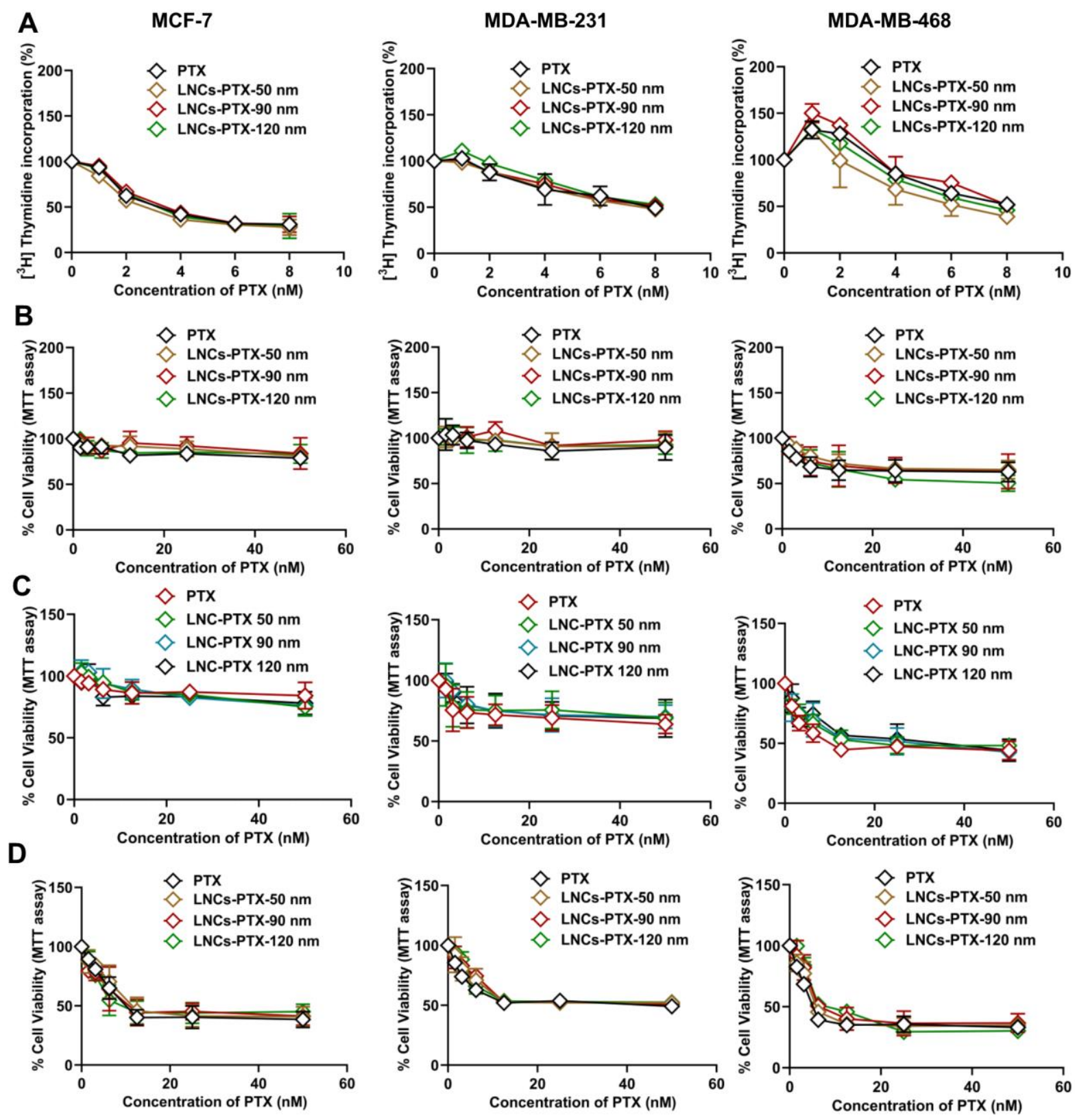

Fig. 3 
A

\begin{tabular}{|c|c|c|}
\hline Endocytic inhibitors & Concentrations & Function \\
\hline $\begin{array}{c}\text { Ethyl-isopropyl } \\
\text { amiloride (EIPA) }\end{array}$ & $30 \mu \mathrm{M}$ & $\begin{array}{c}\text { Inhibitor of macropinocytosis by } \\
\text { blocking } \mathrm{Na}^{+} / \mathrm{H}^{+} \text {exchange }\end{array}$ \\
\hline $\begin{array}{c}\text { Methyl- } \beta \text { - cyclodextrin } \\
\text { (m } \beta \mathrm{CD})\end{array}$ & $2.5 \mathrm{mM}$ & $\begin{array}{c}\text { Cholesterol depletion by } \\
\text { extraction of cholesterol }\end{array}$ \\
\hline Genistein (Gen) & $100 \mu \mathrm{M}$ & $\begin{array}{c}\text { Inhibitor of several protein } \\
\text { tyrosine kinases }\end{array}$ \\
\hline Wortmannin & $1 \mu \mathrm{M}$ & Inhibitor of $\begin{array}{c}\text { phosphatidylinositol } \\
\text { 3-kinase }\end{array}$ \\
\hline ML-141 & $10 \mu \mathrm{M}$ & Inhibitor of the Cdc42 GTPase \\
\hline Latrunculin B (Lat B) & $10 \mu \mathrm{M}$ & Blocks actin polymerization \\
\hline
\end{tabular}

B

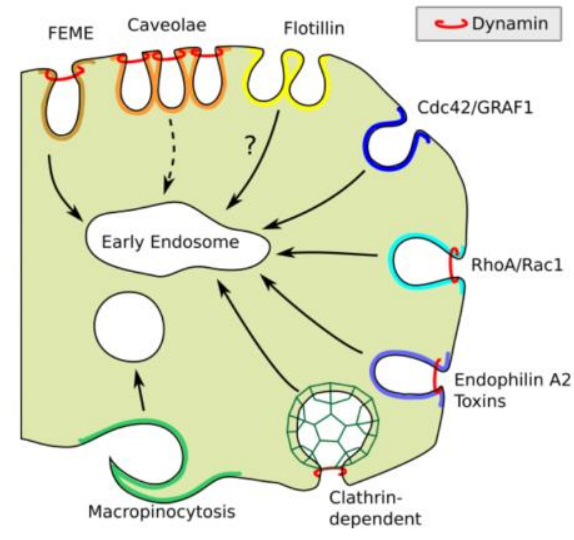

C

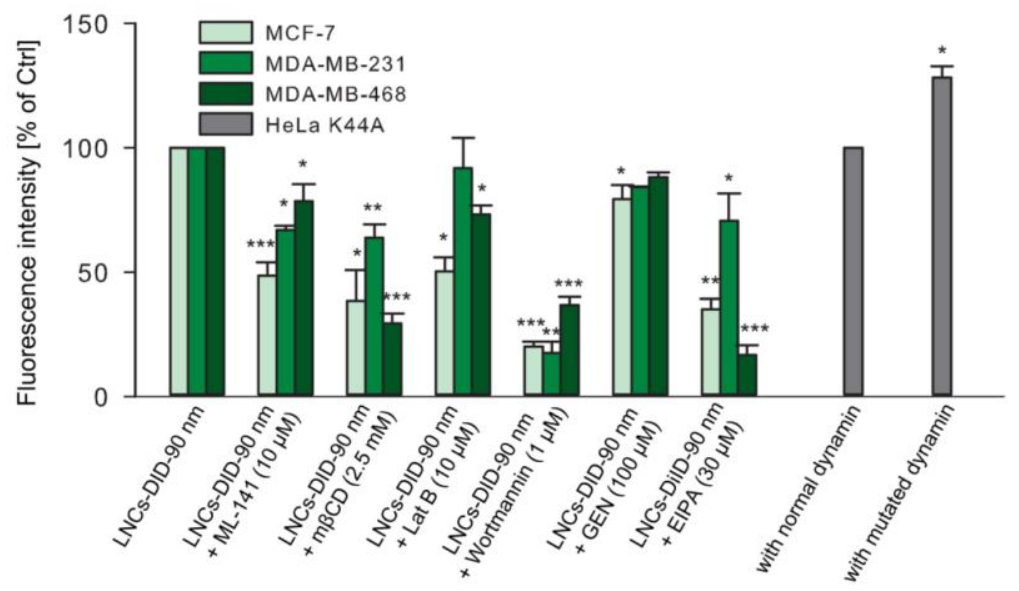

D

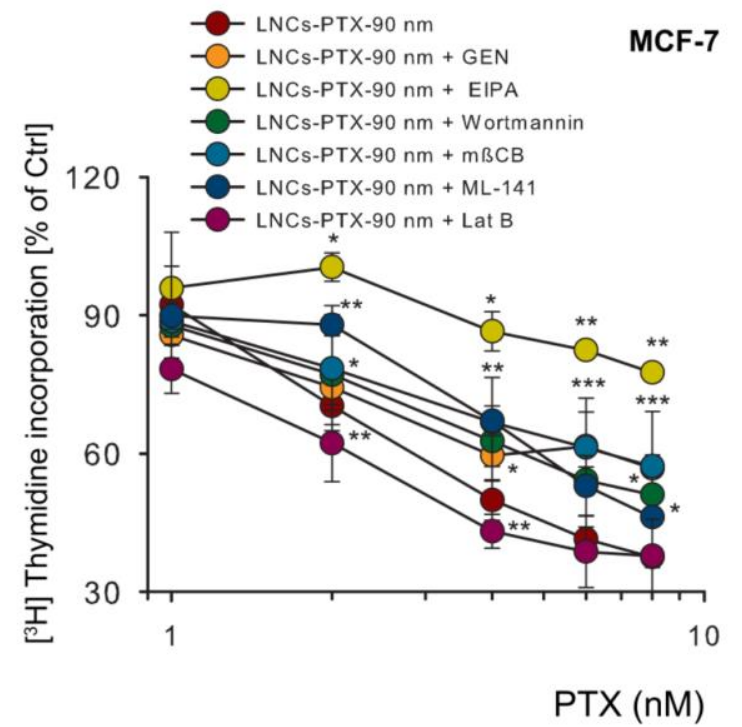

E

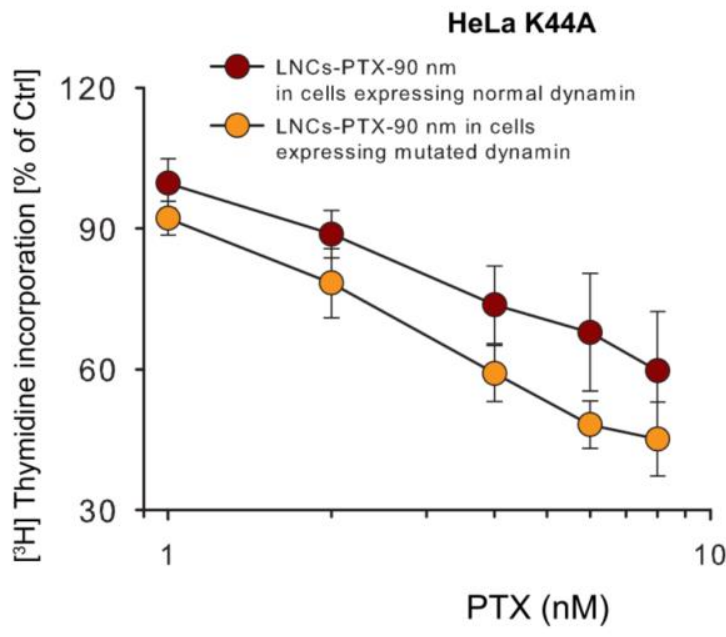

Fig. 4 

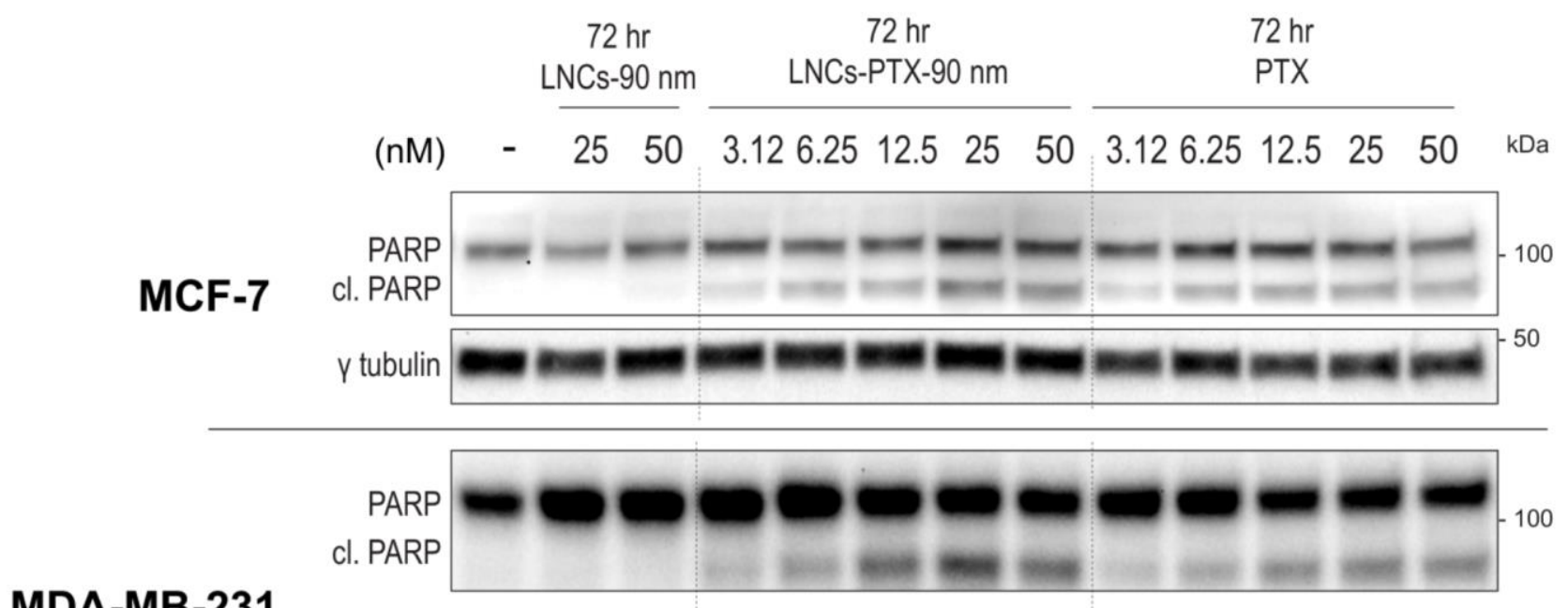

MDA-MB-231

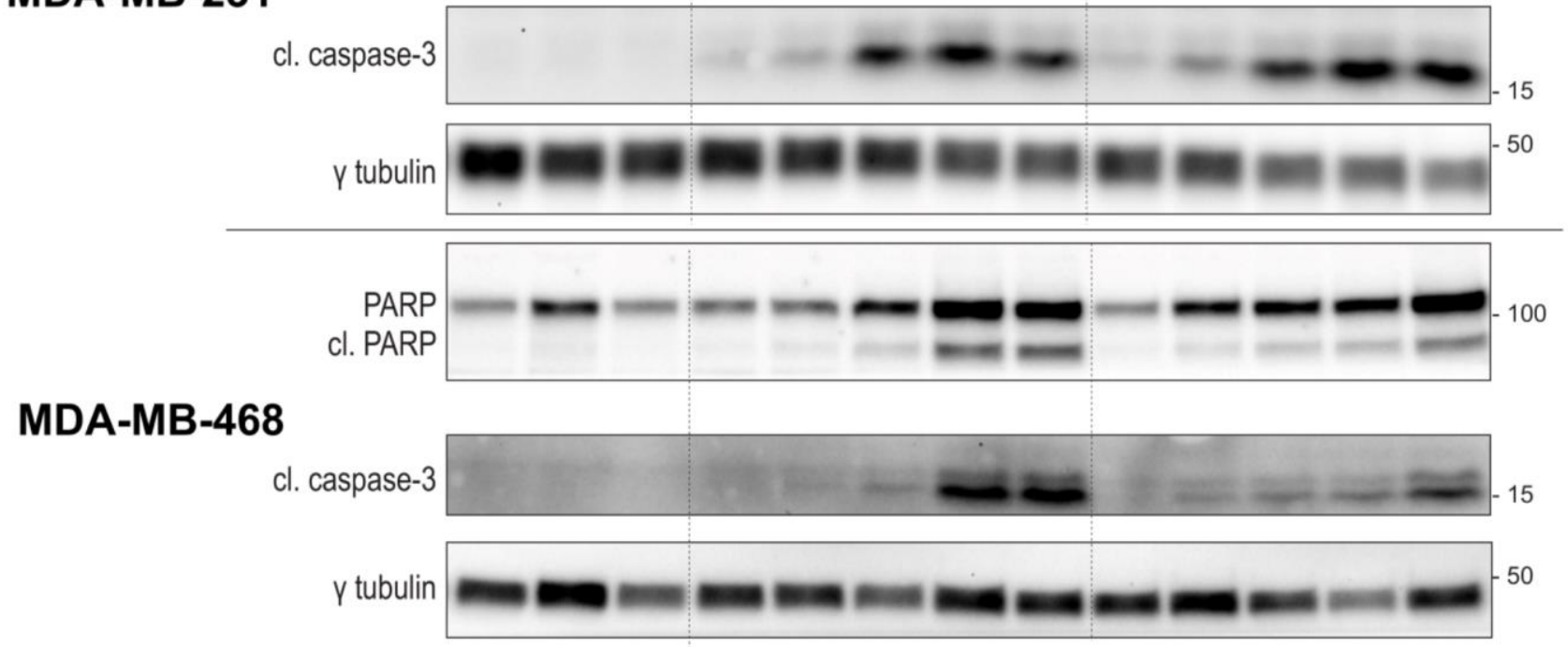

Fig. 5 

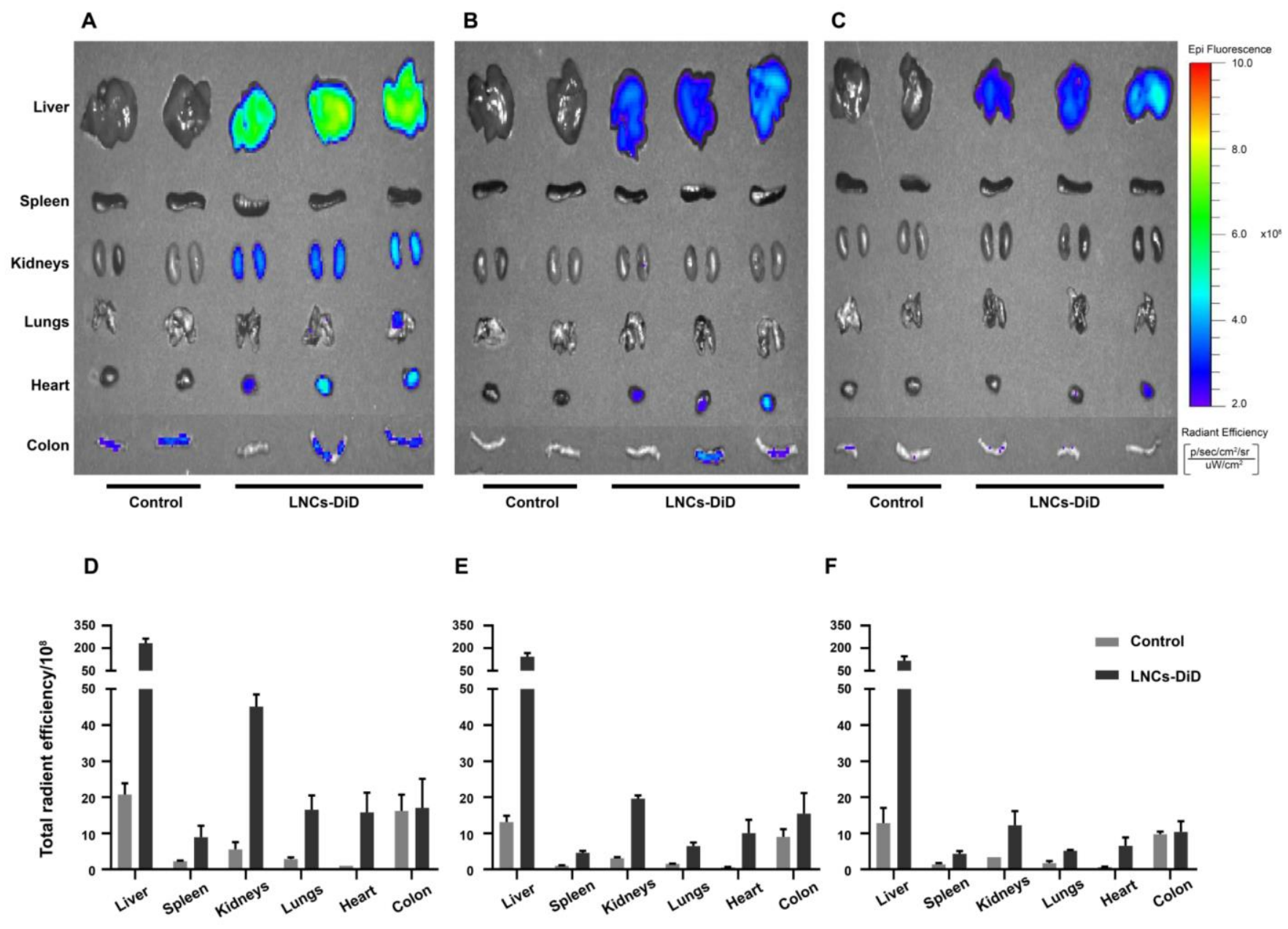

E

F
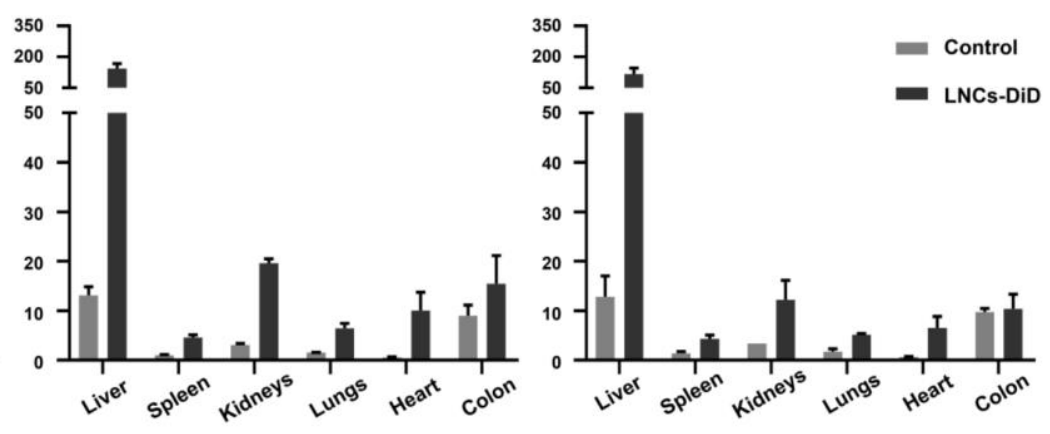

Fig. 6 


\section{Supplementary Information}
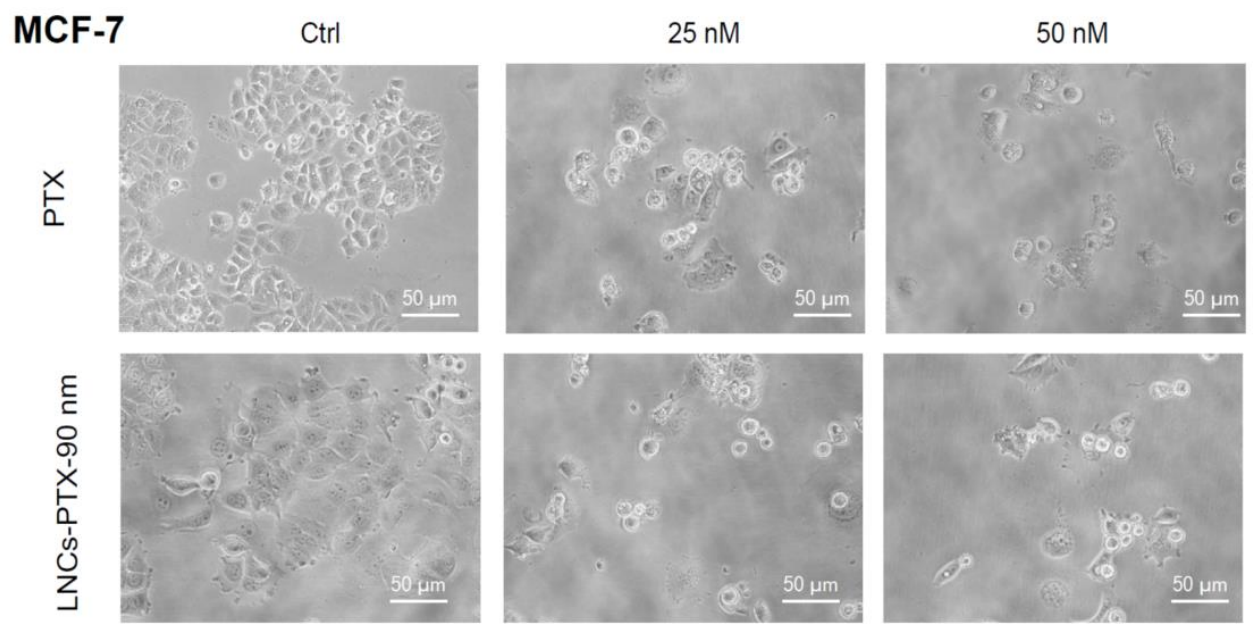

MDA-MB-231 Ctrl

$25 \mathrm{nM}$
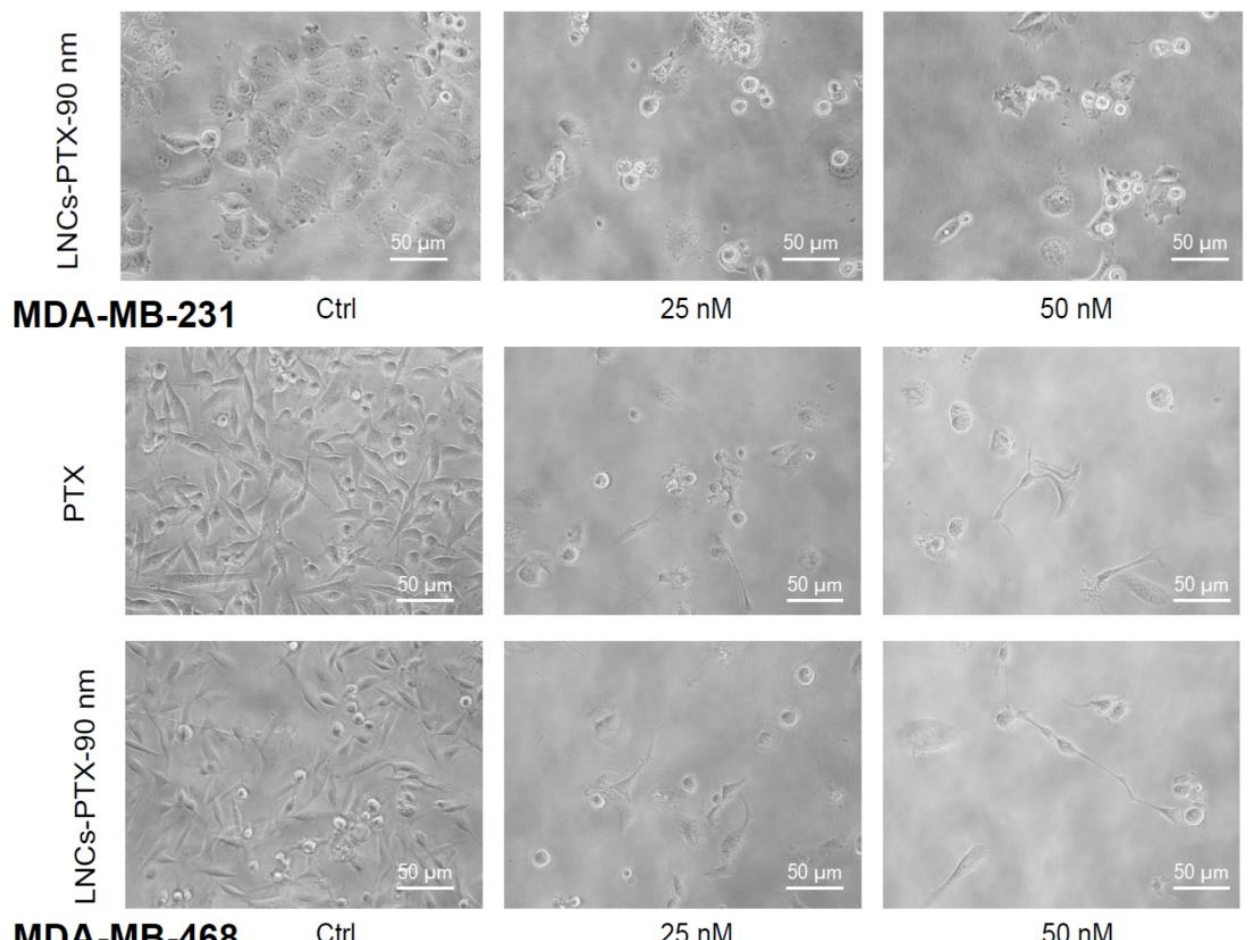

$25 \mathrm{nM}$
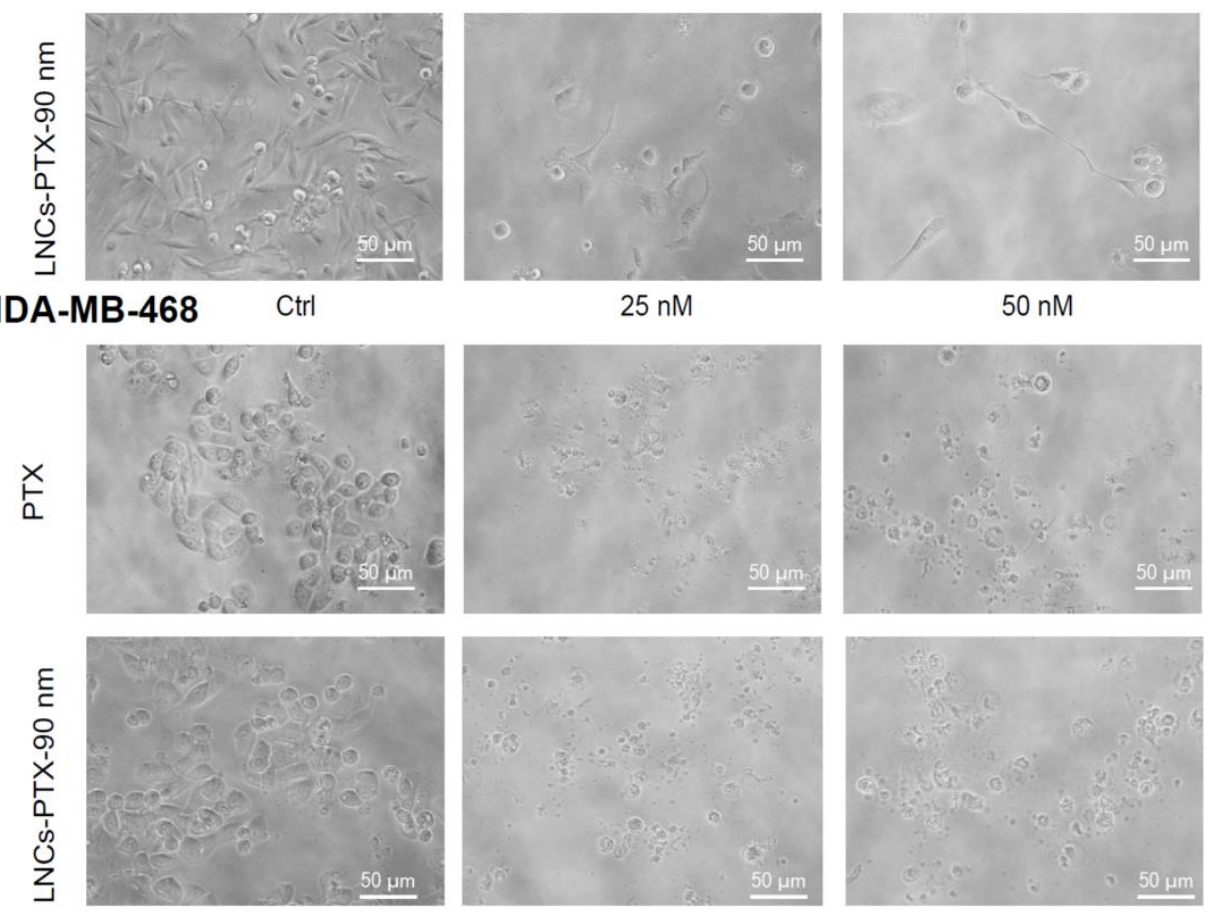

Fig. S1. Morphological changes observed with microscopy. Inverted phase contrast microscopy images were obtained following treatment of MCF-7, MDA-MB-231 and MDA-MB-468 cells for $72 \mathrm{~h}$ with LNCs-PTX-90 $\mathrm{nm}$ or free PTX with the concentrations shown in the figure. Scale bar represents $50 \mu \mathrm{m}$. 


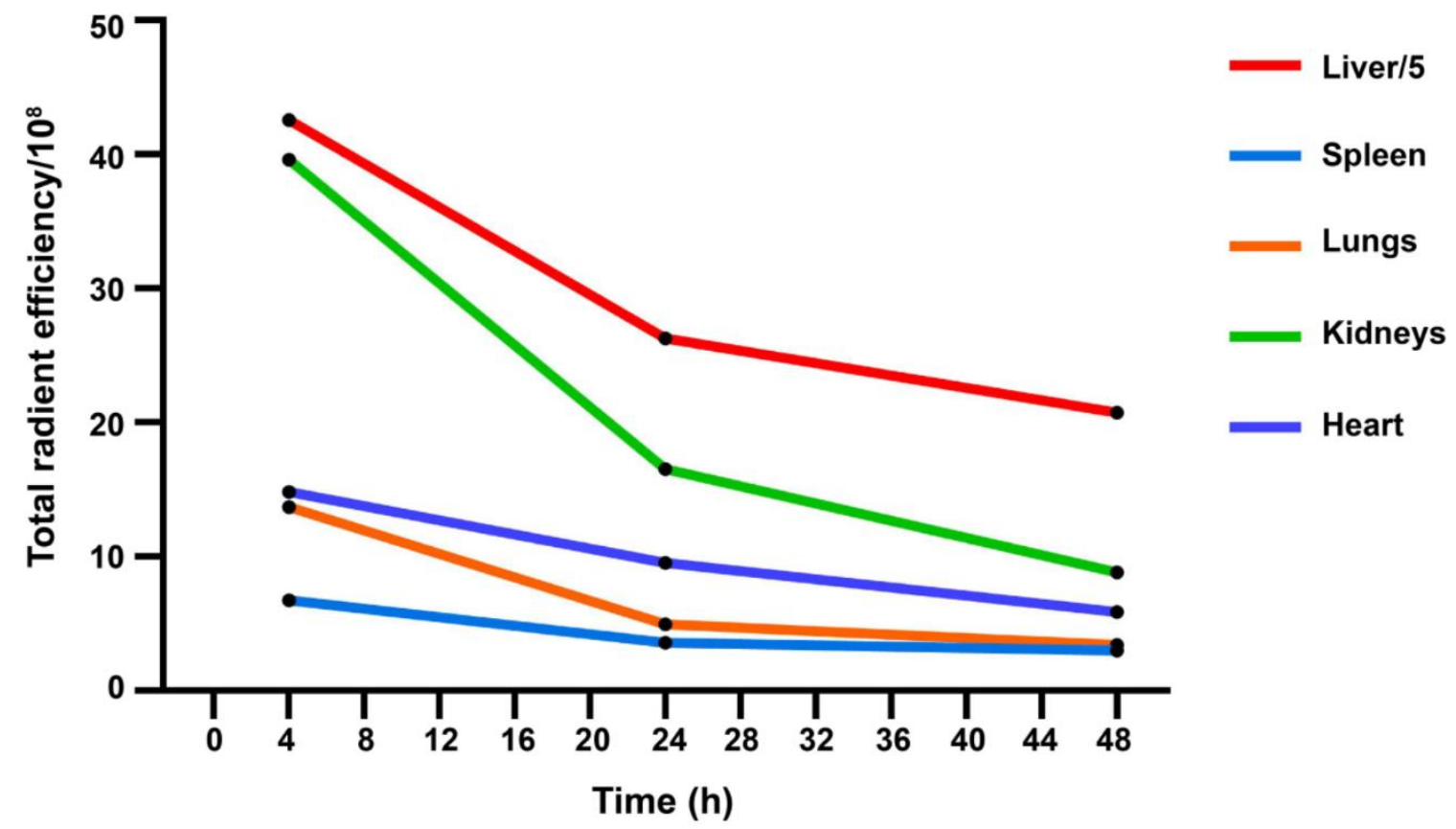

Fig. S2. Decrease in fluorescence from organs following i.v. injection in mice. The data shown in Fig. 6 were used to generate this figure. The fluorescence of the various organs obtained at 4 , 24 and $48 \mathrm{~h}$ after injection of LNCs-DiD-90 $\mathrm{nm}$ were withdrawn the signals from organs of control mice. Since the uptake of LNCs in liver was much higher than in other organs, the liver values were divided by 5 in the present figure to facilitate a comparison of the liver data with those for the other organs. 